\title{
Transcatheter aortic valve implantation in degenerated surgical aortic valves
}

\author{
Giuseppe Tarantini ${ }^{1 *}$, MD, PhD; Danny Dvir², MD; Gilbert H.L. Tang ${ }^{3}$, MD, MSc, MBA \\ 1. Department of Cardiac, Thoracic and Vascular Sciences and Public Health, University of Padua, Padua, Italy; 2. Jesselson \\ Integrated Heart Centre, Shaare Zedek Medical Center, Hebrew University, Jerusalem, Israel; 3. Department of Cardiovascular \\ Surgery, Mount Sinai Health System, New York, NY, USA
}

This paper also includes supplementary data published online at: https://eurointervention.pcronline.com/doi/10.4244/EIJ-D-21-00157

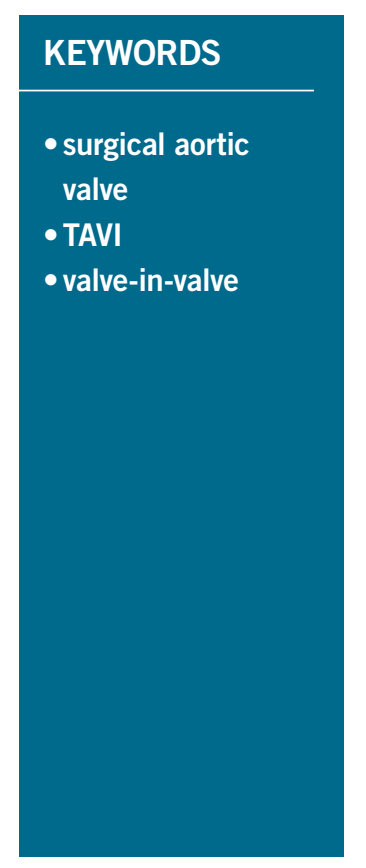

\begin{abstract}
Transcatheter aortic valve implantation (TAVI) within failed bioprosthetic surgical aortic valves (valve-invalve TAVI) has become an established procedure, currently approved for patients deemed at high risk for repeat aortic valve intervention. Although less invasive than surgical reoperation, challenges of valve-invalve treatment include higher rates of malposition, prosthesis-patient mismatch and coronary obstruction. Thus, optimal patient selection and preprocedural planning is of the utmost importance to minimise the risk of these complications. In this review article we provide a fully illustrated overview of the most significant periprocedural operative considerations for valve-in-valve TAVI.
\end{abstract}

*Corresponding author: Department of Cardiac, Thoracic, Vascular Sciences and Public Health, University of Padua, Via Giustiniani 2, 35128 Padua, Italy.E-mail: giuseppe.tarantini.1@gmail.com 


\section{Abbreviations}

BASILICA bioprosthetic aortic scallop intentional laceration to prevent iatrogenic coronary artery obstruction

BVF

BVR

CEPD

PPM

PVL

SAVR

SVD

TAVI

THV

ViV

VTSTJ

balloon valve fracture

balloon valve remodelling

cerebral embolic protection device

prosthesis-patient mismatch

paravalvular leak

surgical aortic valve replacement

structural valve deterioration

transcatheter aortic valve implantation

transcatheter heart valve

valve-in-valve virtual transcatheter heart valve to sinotubular junction distance

\section{Introduction}

In the last decade, bioprosthetic valves have been increasingly implanted instead of mechanical valves. These devices are prone to degeneration and failure. A concern is the potential for an upcoming pandemic of bioprosthesis failure, particularly as younger patients are treated with bioprosthetic valves ${ }^{1}$. Given that some of these patients may not be surgical candidates, valve reintervention may require a less invasive approach. The volume of valve-in-valve ( ViV) transcatheter aortic valve implantation (TAVI) is expected to grow significantly. Current devices and techniques have been successful in the treatment of most degenerated bioprosthetic valves. The main limitations of ViV TAVI are directly related to the lack of space in the aortic root (i.e., residual elevated gradients, severe prosthesis-patient mismatch [PPM]) and mechanical complications related to the deflection of surgical bioprosthetic valve leaflets (i.e., coronary obstruction). This review provides a contemporary overview of the preprocedural evaluation, procedural technique and clinical outcomes in ViV TAVI.

\section{TYPES OF SURGICAL BIOPROSTHETIC AORTIC VALVE}

There are numerous bioprosthetic heart valve designs with different proprietary anticalcification treatments. These devices differ in their tissue characteristics, frame designs and implantation methods. They commonly have an unique fluoroscopic appearance, which is essential for optimal ViV TAVI deployment. Surgical bioprosthetic valves are commonly stratified according to the type of tissue (porcine versus bovine pericardial) or according to the frame (stented, stentless, or sutureless valves). Initially, most surgical bioprosthetic aortic valves were implanted at the plane of the annulus (intra-annular), but they were limited by reduced effective orifice area. The current surgical bioprosthetic aortic valves are implanted above the annulus (supra-annular), allowing a larger effective orifice and decreasing the risk of severe PPM. In addition, tissue leaflets are conventionally mounted to the internal aspect of the stent posts; however, several surgical bioprosthetic valves are designed with externally mounted leaflets, e.g., Mitroflow (LivaNova PLC/Sorin Group, Saluggia, Italy) and Trifecta ${ }^{\mathrm{TM}}$ (Abbott, Minneapolis, MN, USA). While these valves may have a better haemodynamic profile and reduce the risk of severe PPM, the risk of coronary obstruction following ViV TAVI is higher in certain anatomic conditions. In the future, improvements in surgical valve design, such as the expandable hinge in the INSPIRIS surgical aortic valve (SAV) (Edwards Lifesciences, Irvine, CA, USA), may facilitate ViV TAVI by being able to accommodate a larger transcatheter heart valve (THV) to reduce the risk of PPM.

\section{MECHANISMS OF FAILURE IN SURGICAL BIOPROSTHETIC AORTIC VALVES}

There are several common aetiologies for surgical bioprosthetic heart valve failure, according to the Valve Academic Research Consortium (VARC)-3 criteria ${ }^{2}$ (Table 1).

\section{Table 1. Main aetiologies for failure of surgical bioprosthetic heart valves.}

\begin{tabular}{|l|}
\hline Structural valve deterioration (SVD) \\
\hline Non-structural valve dysfunction \\
\hline Paravalvular regurgitation \\
\hline Prosthesis-patient mismatch \\
\hline Valve thrombosis \\
\hline Endocarditis \\
\hline
\end{tabular}

In general, mechanical valves are prone to thrombosis, while bioprosthetic valves are prone to valve deterioration. Structural valve deterioration (SVD) is defined as intrinsic permanent changes to the prosthetic valve, including wear and tear, leaflet disruption, flail leaflet, leaflet fibrosis and/or calcification, and strut fracture, manifested as stenosis and/or regurgitation. The proposed definition of SVD from the European Association of Percutaneous Cardiovascular Interventions (EAPCI) endorsed by the European Society of Cardiology (ESC) and the European Association for Cardio-Thoracic Surgery (EACTS) is shown in Table 2. In general,

Table 2. Proposed definition of structural valve deterioration (SVD) - European Association of Percutaneous Cardiovascular Interventions (EAPCI) endorsed by ESC and EACTS (2017).

\begin{tabular}{|l|l|}
\hline Stage 0 (no SVD) & \multicolumn{1}{|c|}{ Echocardiographic findings } \\
\hline $\begin{array}{l}\text { Stage 1 } \\
\text { (morphological SVD) }\end{array}$ & $\begin{array}{l}\text { Intrinsic permanent structural changes to } \\
\text { the prosthetic valve (leaflet integrity or } \\
\text { structure abnormality, leaflet function } \\
\text { abnormality, strut/frame abnormality) }\end{array}$ \\
\hline $\begin{array}{l}\text { Stage 2 (moderate } \\
\text { haemodynamic SVD) }\end{array}$ & $\begin{array}{l}\text { Mean transprosthetic gradient } \geq 20 \mathrm{mmHg} \\
\text { and }<40 \mathrm{mmHg} \\
\text { Mean transprosthetic gradient } \geq 10 \text { and } \\
<20 \text { mmHg change from baseline }\end{array}$ \\
\hline $\begin{array}{l}\text { Moderate intraprosthetic aortic regurgitation, } \\
\text { new or worsening (>1+/4) from baseline }\end{array}$ \\
\hline haemodynamic SVD) & $\begin{array}{l}\text { Mean transprosthetic gradient } \geq 40 \mathrm{mmHg} \\
\text { Mean transprosthetic gradient } \geq 20 \mathrm{mmHg} \\
\text { change from baseline } \\
\text { Severe intraprosthetic aortic regurgitation, } \\
\text { new or worsening }(>2+/ 4) \text { from baseline }\end{array}$ \\
\hline
\end{tabular}


bovine pericardial valves tend to fail more by stenosis, while porcine valves tend to fail more commonly by regurgitation. ViV TAVI is typically considered in patients with SVD rather than non-structural valve dysfunction, although patients with severe PPM with suitable anatomy may be considered for ViV TAVI with adjunctive procedures (e.g., balloon valve fracture). Figure 1 depicts different mechanisms of SVD based on transoesophageal echocardiography (TEE) evaluation. Echocardiographic findings to differentiate between structural and non-structural valve deterioration in the presence of high transprosthetic gradients are reported in Table 3.

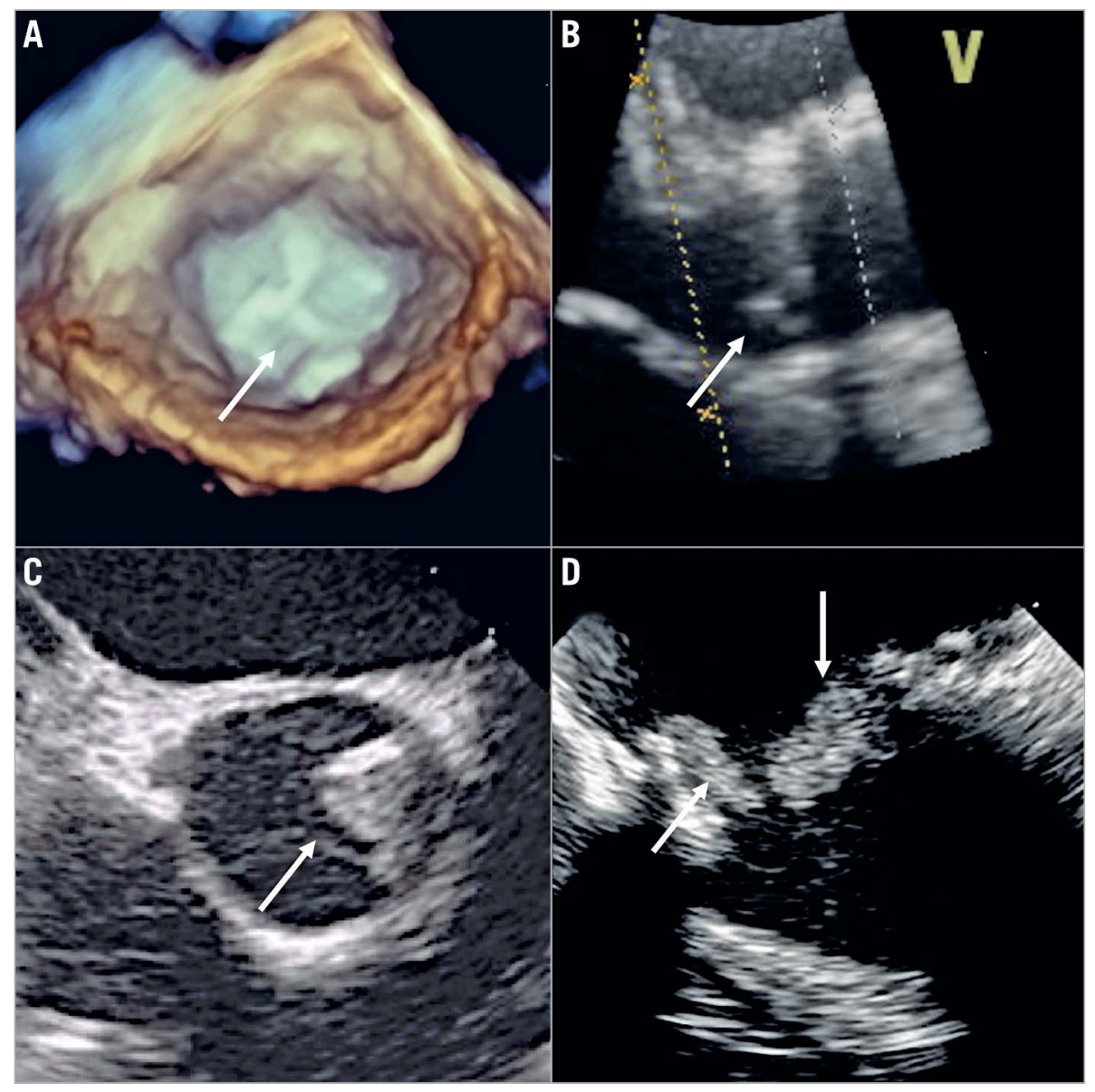

Figure 1. Different mechanisms of aortic bioprosthesis valve dysfunction on transoesophageal echocardiography (TEE) exam. A) Threedimensional TEE image (short-axis view) of a stented bioprosthesis, showing thickened and calcified leaflets (arrow) causing severe stenosis. B) Two-dimensional TEE image (long-axis view) of a stentless bioprosthesis, showing prolapse of the non-coronary cusp (arrow) leading to severe aortic regurgitation. C) Two-dimensional TEE image (short-axis view) of a stentless bioprosthesis, showing a thrombus (arrow) at the level of the non-coronary cusp. D) Two-dimensional TEE image of a stented bioprosthesis, showing endocarditis vegetations (arrows) at the ventricular side.

Table 3. Echocardiographic findings to differentiate between structural and non-structural valve deterioration in the presence of high transprosthetic gradients.

\begin{tabular}{|l|l|l|}
\hline \multicolumn{1}{|c|}{ Normal function } & \multicolumn{1}{c|}{ PPM } & \multicolumn{1}{c|}{ Obstruction } \\
\hline Normal valve structure and motion & Normal valve structure and motion & Abnormal valve structure and motion \\
\hline VPeak $<3 \mathrm{~m} / \mathrm{s}$, MeanG $<20 \mathrm{mmHg}$ & VPeak $>3 \mathrm{~m} / \mathrm{s}$, MeanG $>20 \mathrm{mmHg}$ & VPeak $>3 \mathrm{~m} / \mathrm{s}, \mathrm{MeanG}>20 \mathrm{mmHg}$ \\
\hline $\mathrm{EOA}>1 \mathrm{~cm}^{2} ; \mathrm{DVI} \geq 0.35$ & EOA $>1 \mathrm{~cm}^{2} ; \mathrm{DVI} 0.25-0.34$ & EOA variable; DVI $<0.25$ \\
\hline EOA within normal range & EOA normal & EOA reduced \\
\hline EOAi $>0.85 \mathrm{~cm}^{2} / \mathrm{m}^{2}$ & EOAi $\leq 0.85 \mathrm{~cm}^{2} / \mathrm{m}^{2}$ & EOAi $\leq 0.85 \mathrm{~cm}^{2} / \mathrm{m}^{2}$ \\
\hline $\begin{array}{l}\text { Increase in MeanG }<10 \mathrm{mmHg} \text { and decrease } \\
\text { in EOA }<0.3 \mathrm{~cm}^{2} \text { during follow-up }\end{array}$ & $\begin{array}{l}\text { Increase in MeanG }<10 \mathrm{mmHg} \text { and decrease } \\
\text { in EOA }<0.3 \mathrm{~cm}^{2} \text { during follow-up }\end{array}$ & $\begin{array}{l}\text { Increase in MeanG } \geq 10 \mathrm{mmHg} \text { and decrease } \\
\text { in EOA } \geq 0.3 \mathrm{~cm}^{2} \text { during follow-up }\end{array}$ \\
\hline $\begin{array}{l}\text { DVI: Doppler velocity index; EOA: effective orifice area; EOAi: indexed effective orifice area; MeanG: mean gradient; PPM: prosthesis-patient mismatch; } \\
\text { Vpeak: peak velocity }\end{array}$
\end{tabular}




\section{INDICATIONS FOR REDO SURGICAL AORTIC VALVE REPLACEMENT VERSUS ViV TAVI}

There are no randomised trials offering clear indications on the best treatment choice. Current indications for ViV TAVI in a failing surgical bioprosthetic aortic valve include patients with SVD who are deemed high or extreme risk for reoperative surgical aortic valve replacement (SAVR). Intermediate or low surgical risk patients should be considered for redo SAVR unless anatomically unfavourable. Younger patients, where valve durability would be important, should also be considered for redo SAVR given the unknown long-term durability of ViV TAVI. Redo SAVR should also be considered in patients who have high-risk anatomy for coronary obstruction in ViV TAVI, where bioprosthetic aortic scallop intentional laceration to prevent iatrogenic coronary artery obstruction (BASILICA) is not feasible or when commissural alignment of the THV is necessary to avoid one of its commissural posts obstructing the split bioprosthetic valve leaflet. In patients with non-structural valve dysfunction, such as severe PPM or paravalvular leak (PVL), redo SAVR should be considered if balloon valve fracture (BVF) cannot be safely performed in the stented SAV or percutaneous treatment of the PVL is not feasible. A summary of criteria suggesting reoperative SAVR versus ViV TAVI is provided in Table 4.

\section{PREPROCEDURAL PLANNING AND PROCEDURAL ASPECTS OF ViV TAVI}

\section{EVALUATING TYPES AND DIMENSIONS OF SURGICAL VALVES}

Knowledge of the surgical bioprosthesis is critical to determine the feasibility of ViV TAVI and for procedural planning. An overview of commonly implanted SAVs is shown in Supplementary Figure 1-Supplementary Figure 3. The manufacturer, model and size of the SAV can be obtained either from the original operative report or from the implant card. Imaging modalities, such as fluoroscopy and computed tomography (CT), can also identify the above information.

The valve-in-valve (aortic) mobile application, developed by Vinayak Bapat, is an invaluable planning tool to educate operators on the anatomy of SAV, assess ViV TAVI feasibility and provide guidance on the ViV TAVI procedure ${ }^{3}$. Examples of how to use the valve-in-valve app are shown in Supplementary Figure 4.

As previously mentioned, SAVs can be divided into stented, stentless and sutureless tissue valves. The most common types of bioprosthetic SAV implanted worldwide are stented valves. Each model comes with a manufacturer labelled size which does not represent the true internal diameter (ID) of the prosthesis ${ }^{4}$. Stent ID, measuring the diameter of the stent frame alone, differs from the true ID depending on the type of stented SAV and how the tissue leaflets are mounted onto the stent frame (Figure 2, Figure 3). Supplementary Table 1 shows the main preprocedural features to consider at CT scan evaluation. In particular, a step-by-step approach to measure internal diameters of bioprosthetic SAVs is reported in Supplementary Figure 5.
Table 4. Characteristics to consider when evaluating a patient for redo surgical aortic valve replacement (SAVR) versus valve-invalve (ViV) transcatheter aortic valve implantation (TAVI).

\begin{tabular}{|c|c|c|}
\hline Characteristics & $\begin{array}{l}\text { Redo SAVR } \\
\text { favoured }\end{array}$ & $\begin{array}{c}\text { TAV-in-SAV } \\
\text { favoured }\end{array}$ \\
\hline \multicolumn{3}{|l|}{ Patient } \\
\hline Low/intermediate surgical risk & $\checkmark$ & \\
\hline High/extreme surgical risk & & $\checkmark$ \\
\hline Age $\geq 80$ & & $\checkmark$ \\
\hline $\begin{array}{l}\text { Young age }(<75) \text { where valve } \\
\text { durability is important }\end{array}$ & $\checkmark$ & \\
\hline $\begin{array}{l}\text { Concomitant diseases needing } \\
\text { surgical intervention }\end{array}$ & $\checkmark$ & \\
\hline $\begin{array}{l}\text { Significant paravalvular leak not } \\
\text { amenable to percutaneous closure }\end{array}$ & $\checkmark$ & \\
\hline Patient preference & $\checkmark$ & $\checkmark$ \\
\hline \multicolumn{3}{|l|}{ Surgical valve } \\
\hline $\begin{array}{l}\text { Small size where severe PPM } \\
\text { cannot be addressed }\end{array}$ & $\boldsymbol{\nu}$ & \\
\hline Large size without severe PPM & & $\checkmark$ \\
\hline $\begin{array}{l}\text { Balloon valve fracture feasible and } \\
\text { low risk }\end{array}$ & & $\boldsymbol{v}$ \\
\hline $\begin{array}{l}\text { Severe PPM when balloon valve } \\
\text { fracture is not feasible or high risk }\end{array}$ & $\checkmark$ & \\
\hline \multicolumn{3}{|l|}{ Anatomic } \\
\hline High risk of coronary obstruction & $\checkmark$ & \\
\hline High risk of THV malposition & $\checkmark$ & \\
\hline High risk of aortic root injury & $\checkmark$ & \\
\hline Favourable coronary anatomy & & $\checkmark$ \\
\hline Calcified aortic root or hostile chest & & $\checkmark$ \\
\hline
\end{tabular}

\section{EVALUATING CORONARY OBSTRUCTION RISK IN VIV TAVI}

Coronary obstruction risk is known to be higher in ViV TAVI than in native TAVI ${ }^{5}$. This is due to the extension of the SAV leaflets beyond the aortic root above the sinotubular junction (STJ). After ViV TAVI, the SAV leaflets are displaced to create a cylinder effect causing sinus sequestration and sealing off flow to the coronaries. To assess the risk of coronary obstruction in ViV TAVI, a multidetector computed tomography (MDCT) scan should be performed and the valve-to-coronary (VTC) and valve-to-STJ (VTSTJ) distances should be measured. Distances $<3 \mathrm{~mm}$ would be considered at high risk of coronary obstruction ${ }^{5}$. The BASILICA procedure can serve as an adjunctive technique in TAV-in-SAV to reduce coronary obstruction risk, by splitting the interfering SAV leaflet prior to TAVI ${ }^{6}$. A Valve-in-Valve International Data (VIVID) classification of aortic root anatomy in TAV-in-SAV has been proposed, together with a decision-making algorithm to guide procedural planning and need for BASILICA (Supplementary Figure 6, Figure 4) ${ }^{7}$. Bear in mind that there is a learning curve associated with the BASILICA procedure and reported stroke rates even in experienced centres were not negligible ${ }^{6}$. Commissural misalignment of the TAV facing the split portion of the SAV leaflet after BASILICA may still 
A

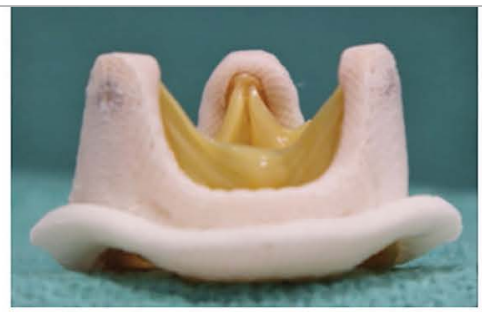

\section{Mosaic, 23}

B

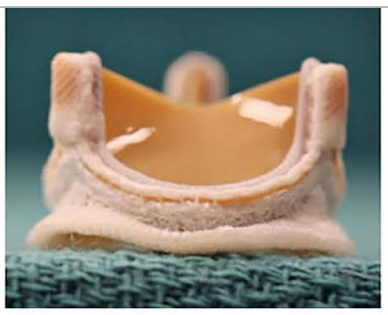

Magna 3000, 23
C

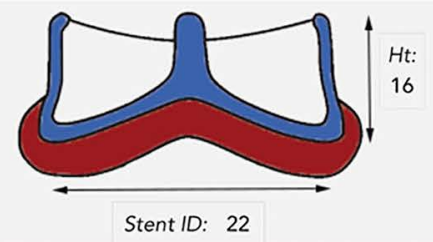

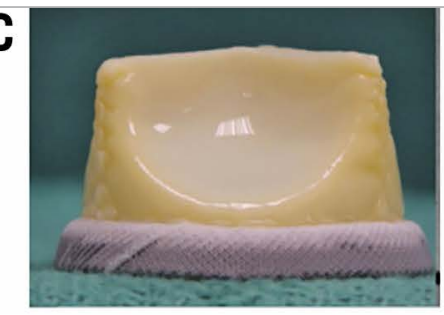

Mitroflow, 23

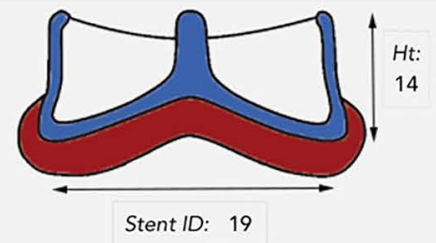

Stent ID: 19

(1. True ID

Figure 2. Examples of stented surgical aortic valves. A) $23 \mathrm{~mm}$ Mosaic ${ }^{\circledR}$ porcine valve (Medtronic). B) 23 mm Magna 3000 pericardial valve (Edwards Lifesciences). C) $23 \mathrm{~mm}$ Mitroflow externally mounted pericardial valve (LivaNova PLC), where the manufacturer labelled size, stent and true internal diameters are different.

cause coronary obstruction. A more conventional technique of coronary stenting (e.g., chimney technique) may be more reproducible and less complex. An example of the CT-based step-by-step approach for the risk of coronary obstruction in ViV TAVI is shown in Supplementary Figure 7-Supplementary Figure 9.

\section{TRANSCATHETER HEART VALVE SELECTION IN ViV TAVI}

The type and size of TAV that can be implanted in a SAV can be found on the valve-in-valve app. A certain degree of oversizing is recommended to avoid TAV migration. Factors to consider when choosing a THV are listed in Table 5.

There is emerging evidence that improved haemodynamic performance of the THV can be achieved by aiming for a higher implant due to improved circularity of the THV and reduced pinwheeling of the leaflets ${ }^{8-10}$. Although balloon predilatation is rarely performed in ViV TAVI, post-dilatation may be beneficial to improve THV frame expansion and circularity to optimise THV leaflet function and
Table 5. Factors to consider before balloon-expandable versus self-expanding transcatheter aortic valve (TAV) implantation in a failing surgical aortic valve (SAV).

\begin{tabular}{|l|c|c|}
\hline \multicolumn{1}{|c|}{ Factors } & $\begin{array}{c}\text { Balloon-expandable } \\
\text { valve preferred }\end{array}$ & $\begin{array}{c}\text { Self-expanding } \\
\text { valve preferred }\end{array}$ \\
\hline $\begin{array}{l}\text { Smaller SAV (true ID } \\
<23 \mathrm{~mm} \text { ) }\end{array}$ & $\boldsymbol{\checkmark}$ \\
\hline $\begin{array}{l}\text { Need for coronary } \\
\text { re-access }\end{array}$ & $\boldsymbol{\checkmark}$ & \\
\hline $\begin{array}{l}\text { Pure aortic regurgitation in } \\
\text { a stentless SAV }\end{array}$ & $\boldsymbol{\checkmark}$ & \\
\hline BVF feasible & & $\checkmark$ \\
\hline BVF not feasible or safe & & \\
\hline
\end{tabular}

haemodynamics. In smaller SAVs (manufacturer size $\leq 23 \mathrm{~mm}$ and in porcine valves $\leq 25 \mathrm{~mm}$ given the smaller stent/true ID), BVF, if deemed feasible and safe, may be considered to allow implantation
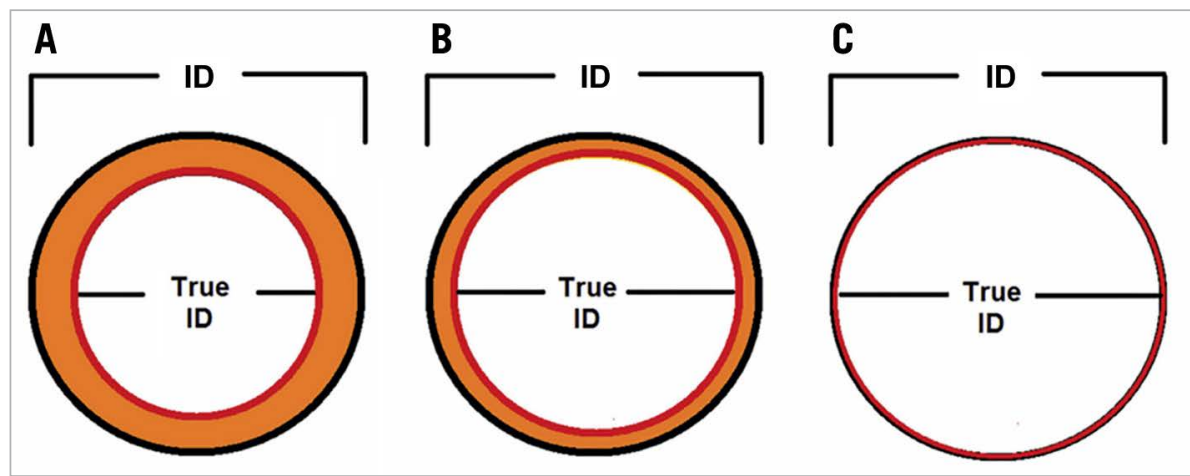

Figure 3. Effect of leaflet type and mounting on the stent and true internal diameter (ID) of stented surgical aortic valves. A) Porcine valves: true internal diameter (ID) is at least $2 \mathrm{~mm}$ less than the stent ID. B) Pericardial valves with leaflets sutured inside the stent frame: true ID is at least $1 \mathrm{~mm}$ less than the stent ID. C) Pericardial valves with leaflets sutured outside the stent frame: true ID is the same as the stent ID. 


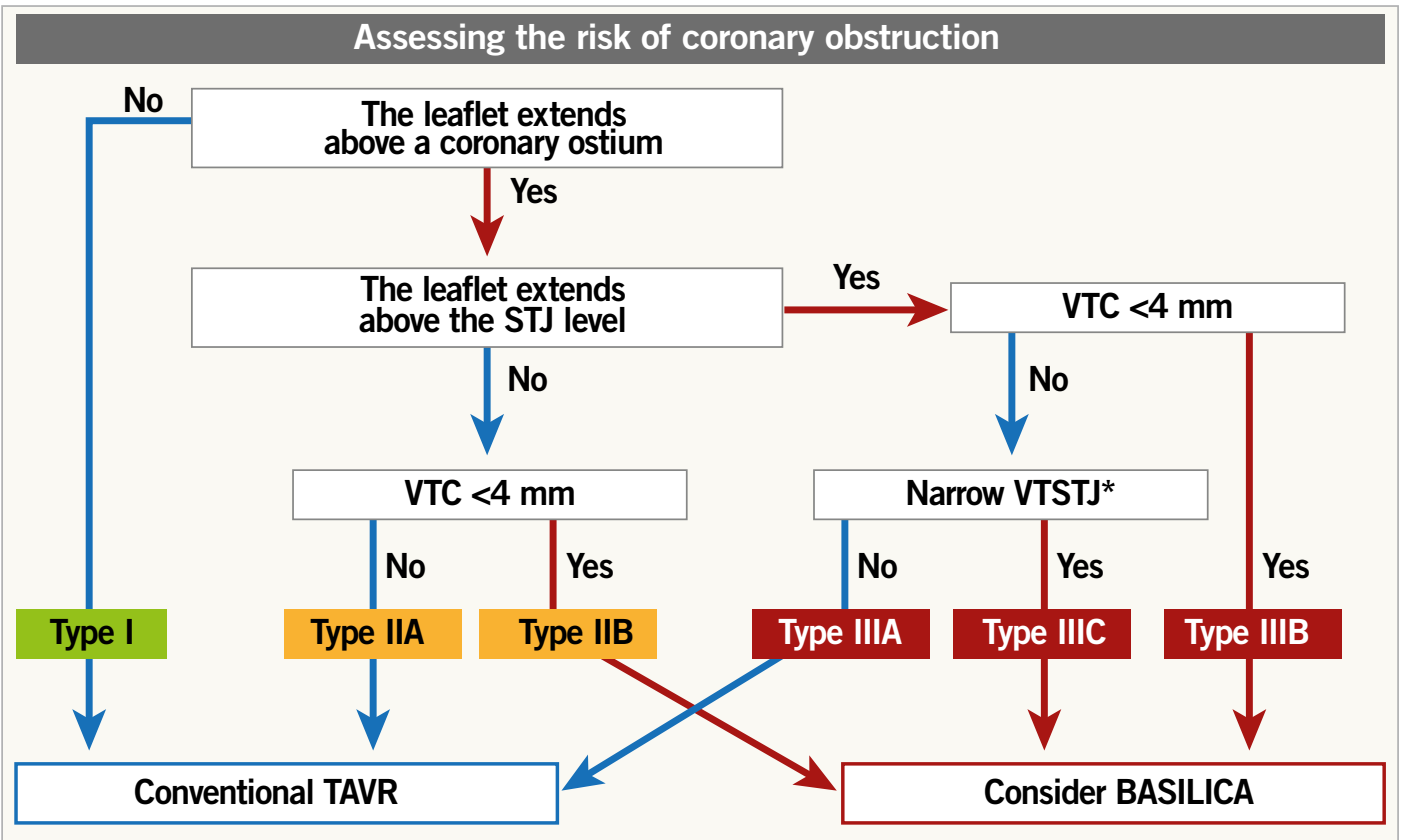

Figure 4. Proposed algorithm to determine aortic root anatomy and indication for BASILICA in ViV TAVI. * Either above, at, or up to $2 \mathrm{~mm}$ below the plane of the STJ. The threshold to define a narrow VTSTJ is unknown and is currently considered as $<2.5-3.5 \mathrm{~mm}(<2.5 \mathrm{~mm}$ is a high-risk condition and 2.5-3.5 mm is an intermediate-risk condition) ${ }^{7}$. BASILICA: bioprosthetic aortic scallop intentional laceration to prevent iatrogenic coronary artery obstruction; STJ: sinotubular junction; TAVR: transcatheter aortic valve replacement; VTC: virtual transcatheter heart valve to coronary distance; VTSTJ: virtual transcatheter heart valve to sinotubular junction distance

of a larger THV or improve expansion of the planned THV in order to optimise haemodynamic performance.

In sutureless SAVs, the target implant depth depends on the specific sutureless valve and the THV size used given the ability to expand the sutureless valve frame. The valve-in-valve app provides guidance on preprocedural planning and implantation technique $^{4}$. In stentless valves including homografts, TAVI positioning and deployment strategies should be similar to those in native TAVI, given the lack of fluoroscopic landmarks and the fact that aortic regurgitation is often the mechanism of SVD.

\section{BALLOON VALVE FRACTURE OR REMODELLING IN VIV TAVI}

In patients with severe PPM associated with smaller SAVs, ViV TAVI will not improve pre-existing PPM given that the THV is implanted within too small a SAV. In patients with severe PPM but no or mild SVD, ViV TAVI is unlikely to be beneficial because it does not modify the underlying PPM. BVF has been proposed as a technique to increase the true ID of the SAV to allow either a larger THV or a better expanded THV to be implanted in order to optimise haemodynamic performance, while potentially reducing the severity of the pre-existing $\mathrm{PPM}^{11}$. The technique involves using a non-compliant balloon to inflate within the SAV at a high pressure to fracture the stented SAV frame, to improve expansion of the implanted TAV or to allow a larger TAV to be implanted without the risk of frame underexpansion.

Not all stented SAVs can undergo BVF (Supplementary Table 2) ${ }^{12}$. Sutureless and stentless SAVs cannot undergo BVF; however, in sutureless valves you can potentially obtain balloon valve remodelling (BVR) by overexpansion. BVF should not be performed in patients with bio-Bentall aortic root replacement with a stented SAV due to the risk of aortic root rupture. This is due to the surgical suture line located at the ventriculo-aortic junction. A non-compliant balloon may disrupt that suture line and cause a potentially fatal tear in the aortic root. BVF may be performed before or after TAVI. The potential advantages and disadvantages of BVF before or after TAVI are listed in Table 6 .

Table 6. Potential advantages and disadvantages of balloon valve fracture (BVF) before or after transcatheter aortic valve implantation (TAVI).

\begin{tabular}{|l|l|l|}
\hline Advantages & \multicolumn{1}{|c|}{ BVF before TAVI } & \multicolumn{1}{c|}{ BVF after TAVI } \\
& $\begin{array}{l}\text { Easier to implant self-expanding valve with less sizing } \\
\text { mismatch } \\
- \text { Can confirm successful fracture before finalising TAV size }\end{array}$ & $\begin{array}{l}\text { - Better TAV expansion, especially in balloon-expandable } \\
\text { valves } \\
- \text { Less risk of acute severe aortic regurgitation }\end{array}$ \\
\hline Disadvantages & $\begin{array}{l}\text { - Acute severe aortic regurgitation causing haemodynamic } \\
\text { collapse } \\
- \text { May need to post-dilate to optimise haemodynamics }\end{array}$ & $\begin{array}{l}\text { - TAV migration or embolisation } \\
\text { - Acute TAV failure from leaflet injury } \\
\text { - Unknown effect on TAV durability }\end{array}$ \\
\hline
\end{tabular}


In terms of balloon selection and sizing, a non-compliant balloon should be selected (e.g., Atlas ${ }^{\mathrm{TM}}$ Gold, True ${ }^{\mathrm{TM}}$ balloon [both Becton, Dickinson and Company, Franklin Lakes, NJ, USA]). The ideal balloon size should always be more than the true ID and be at least equal to the stent ID if not the manufacturer label size. When doing BVF after TAVI, the balloon should be positioned, when feasible, to reduce contact with the THV leaflets in order to avoid injury. Using a $60 \mathrm{~mL}$ syringe plus an indeflator assembly connected with a high-pressure 3-way stopcock, under rapid ventricular pacing, the syringe is quickly emptied to inflate the balloon, then switched to cranking the indeflator to achieve high-pressure inflation ${ }^{13}$. The balloon waist release at fluoroscopy is associated with a sudden drop in inflation pressure. The balloon is then deflated and removed carefully to avoid the risk of THV migration.

Complications from BVF include acute severe aortic regurgitation from SAV causing haemodynamic collapse, THV migration, coronary obstruction, aortic root injury and THV failure due to balloon injury to the leaflets.

\section{STROKE RISK AND CEREBRAL EMBOLIC PROTECTION}

Degenerated surgical bioprostheses may be heavily calcified and/or friable, and prone to leaflet tearing. Despite this, no significant difference in stroke rate has been demonstrated between TAV-in-SAV procedures and TAVI for native aortic valve steno$\mathrm{sis}^{14}$. Therefore, a cerebral embolic protection device (CEPD) should be used based on the operative risk factors (e.g., complex valve-in-valve procedures with expected increased catheter manipulation, multiple valve repositioning manoeuvres, need for predilatation and post-dilatation/BVF, and BASILICA procedure).

\section{ANTITHROMBOTIC REGIMEN}

Patients who are candidates for $\mathrm{ViV}$ procedures usually have multiple comorbidities, leading to a higher risk of both thrombotic and bleeding events, which require optimal antithrombotic management. In the absence of randomised data, the optimal antithrombotic regimen after ViV procedures should be based on the patient's specific anatomical (e.g., higher risk of leaflet thrombosis and sinus sequestration) and clinical (e.g., other indications for anticoagulant therapy such as atrial fibrillation) characteristics. Regardless of the periprocedural and early antithrombotic regimen, a careful and close clinical and echocardiographic monitoring for early recognition of signs of valve thrombosis and new onset of atrial fibrillation is also of the utmost importance in ViV patients.

\section{CORONARY ACCESS AFTER VIV TAVI}

Factors affecting the feasibility of coronary access after ViV TAVI are largely similar to those related to the risk of acute coronary obstruction during the index procedure ${ }^{7}$ (Figure 5). With the implantation of the transcatheter valve, the leaflets of the degenerated surgical prosthesis will be tilted up, thereby creating a cylindric covered stent through which a catheter will not be able to penetrate towards the coronary ostium. The height of this barrier (i.e., "neoskirt") ${ }^{15-18}$ is determined by the length of the degenerated SAV leaflets. To anticipate the unfeasibility of coronary access after ViV TAVI, the following factors need to be evaluated:-

1. Location of the coronary ostium in relation to the neoskirt This depends on both coronary ostium height and type of surgical bioprosthesis (and height of SAV implantation). Coronary cannulation will be easier if the ostium is above the neoskirt

\section{A Factors impacting coronary access after TAV-in-SAV}

\section{Anatomical \\ 1. STJ dimensions \\ 2. Sinus height \\ 3. Sinus width \\ 4. Coronary height}

\section{Device/Procedural}

1. SAV type

2. SAV leaflet length

3. TAV type

4. VTC/VTSTJ

5. TAV implantation depth

6. TAV orientation

\section{B Sub-coronary risk plane}
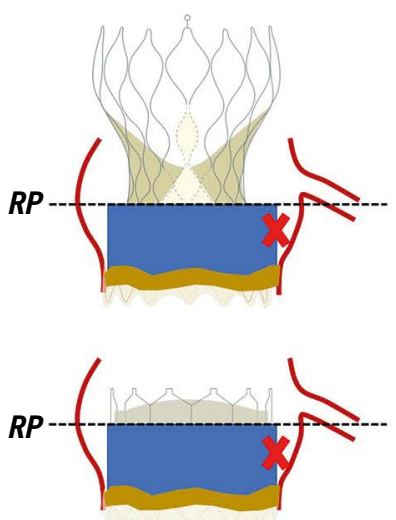

Easier coronary access, depending on TAV alignment
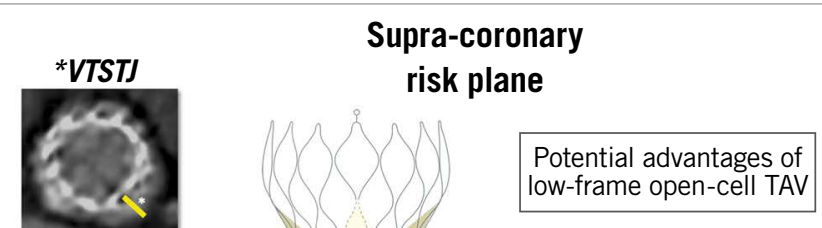

VTSTJ $>2 \mathrm{~mm}$
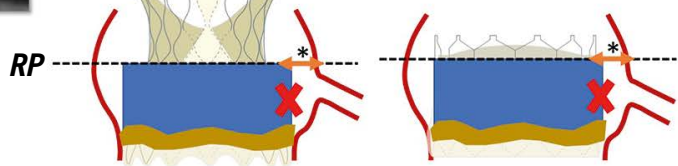

VTSTJ $<2 \mathrm{~mm}$

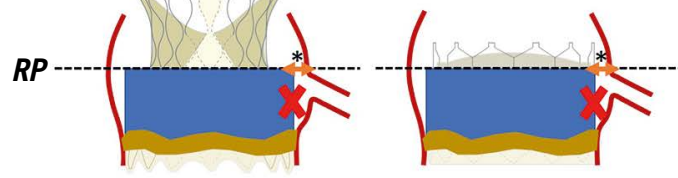

Figure 5. Factors impacting coronary access after TAV-in-SAV in prostheses with a sub-coronary or supra-coronary risk plane. A) Factors impacting coronary access after TAV-in-SAV. B) Sub-coronary risk plane and supra-coronary risk plane. RP: risk plane; SAV: surgical aortic valve; TAV: transcatheter aortic valve; VTC: virtual transcatheter heart valve to coronary distance; VTSTJ: virtual transcatheter heart valve to sinotubular junction distance 
(type I), particularly if the THV type used for ViV TAVI has an open-cell design ${ }^{19-21}$ (Figure 6A).

2. Sinotubular junction dimensions

If the coronary ostium is located below the neoskirt, coronary cannulation is theoretically feasible only in the presence of a large STJ (type IIa and IIIa). Nevertheless, even in the presence of a large STJ junction, although the deployment of the THV might not cause a complete impairment of coronary flow (i.e., acute coronary obstruction), the VTSTJ might be not wide enough to allow selective coronary cannulation (Figure 6B). In this situation, percutaneous coronary intervention will be difficult, if not impossible.

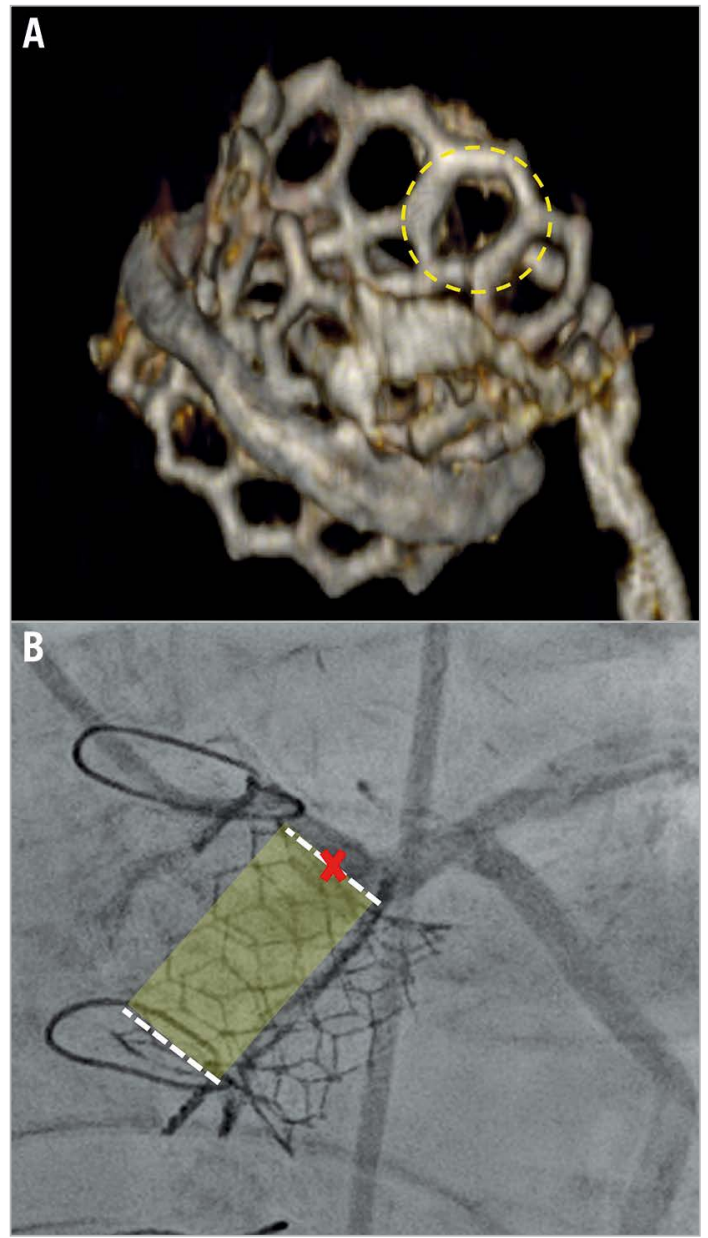

Figure 6. Two cases of ViV TAVI. A) Valve-in-valve TAVI with a SAPIEN 3 valve (Edwards Lifesciences). The dotted circle identifies an open cell in the upper part of the stent frame. B) A case of ViV TAVI with a small VTSTJ in which the coronary artery could not be selectively engaged despite the implantation of a low-frame prosthesis with large cell size.

3. Type of transcatheter heart valve

Irrespective of aortic root anatomy, use of a low frame THV is advantageous as compared to a taller frame device with regard to coronary cannulation. This is particularly true in the case of type IIa and IIIa anatomies. Importantly, available supra-annular devices have higher asymmetric commissures (Figure 7A). If a commissure lands in front of the coronary ostium because of THV misalignment (Figure 7B), coronary cannulation will be non-coaxial and thus particularly difficult if the ostium is located below the neoskirt. The latter issue might be mitigated by the possibility of aligning the THV to the surgical bioprosthesis (i.e., to the native aortic valve). While it has been shown that Evolut ${ }^{\mathrm{TM}}$ (Medtronic, Minneapolis, MN, USA) and ACURATE (Boston Scientific, Marlborough, MA, USA) THVs might be partially "orientable", other available THVs cannot be aligned $^{22}$.

\section{CLINICAL OUTCOMES AFTER VIV TAVI}

Clinical outcomes after ViV TAVI are different from outcomes after conventional TAVR in several respects ${ }^{23,24}$ (Table 7).

\section{Table 7. Comparison of issues in ViV TAVI versus native TAVI.}

\begin{tabular}{|l|c|c|c|}
\hline & $\begin{array}{c}\text { Stented } \\
\text { VIV TAVI }\end{array}$ & $\begin{array}{c}\text { Stentless } \\
\text { ViV TAVI }\end{array}$ & $\begin{array}{c}\text { Native } \\
\text { TAVI }\end{array}$ \\
\hline Residual elevated gradient & ++ & + & + \\
\hline Clinical thrombosis & ++ & + & + \\
\hline Coronary obstruction & ++ & +++ & + \\
\hline Device malpositioning & + & ++ & + \\
\hline Paravalvular leak & - & ++ & + \\
\hline Annular rupture & $-{ }^{*}$ & + & + \\
\hline
\end{tabular}

*Annular rupture may occur in balloon valve fracture. + denotes higher likelihood while - denotes lower likelihood of occurrence.

A matched comparison between conventional TAVI and ViV TAVI showed lower mortality in the ViV group, that persisted after adjusting for differences in baseline characteristics ${ }^{23}$. The frame of stented bioprosthetic valves enables protection to surrounding structures when a valve is implanted inside. As a result, the risk of mechanical complications such as annular injury and damage to the aortomitral curtain is lower in ViV TAVI. Similarly, conduction defects are lower, with the rate of pacemaker implantation after ViV TAVI consistently below 10\%. The frame of the stented bioprosthetic valves also enables good support for sealing after ViV TAVI and, as a result, the risk of PVL is very low, if the previously implanted valve did not have PVL. On the other hand, some adverse events are more common in ViV TAVI. These include residual elevated gradients (especially in small and stenotic surgical valves), clinical thrombosis, THV malpositioning (especially in regurgitant stentless valves and those with poor fluoroscopic markers), and coronary obstruction.

Clinical outcomes after aortic ViV TAVI are significantly related to the characteristics of the surgical valve. Small and stenotic surgical valves are associated with inferior clinical outcomes. Data from the VIVID Registry, stratifying patients according to the valve size, showed that those with small surgical valves (label size $\leq 21 \mathrm{~mm}$ ) had worse one-year mortality after ViV TAVI than those with intermediate and large surgical valves $(25.2 \% \text { vs } 18.2 \% \text { and } 6.7 \%)^{25}$. 


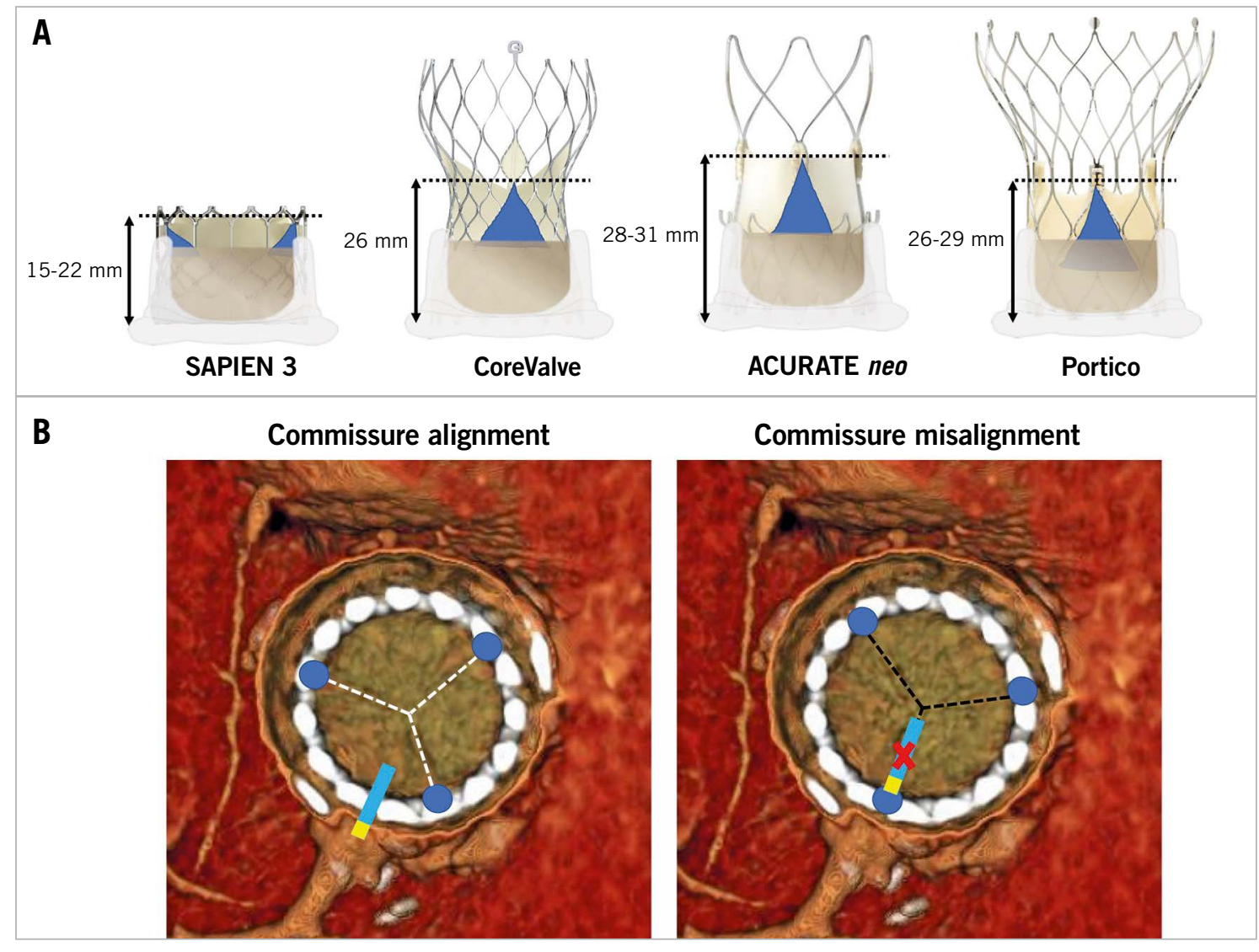

Figure 7. Impact on coronary access of misaligned high THV commissural posts. A) Commissure height of different transcatheter heart valves. B) Examples of neo-commissure alignment versus misalignment with the native coronary ostia.

More contemporary smaller analyses with lower-risk patient populations have shown lower one-year mortality compared to the VIVID Registry ${ }^{23,26}$. The mechanism of failure consistently continues to be linked to the risk of elevated post-procedural gradients.

With greater operator experience and improved devices in comparison to those used a decade ago, the rate of most adverse events after ViV TAVI is decreasing. Nevertheless, post-ViV TAVI elevated gradients remain a significant issue ${ }^{27}$. Elevated gradients are relatively common after ViV TAVI and considered the Achilles' heel of these procedures. Correlates for residual stenosis after ViV TAVI can be divided into preprocedural, procedural and post-procedural characteristics (Table 8). Long-term (8-year) outcomes after ViV TAVI were recently published by the VIVID Registry investigators ${ }^{28}$, with the main correlates for mortality and for reintervention including small true ID, pre-existing severe PPM and the use of balloon-expandable valves.

Supplementary Figure 10 shows different examples of challenging ViV TAVI cases.

\section{Conclusions}

In this review we have tried to encompass all the most relevant and updated achievements in the field of valve-in-valve TAVI. Specifically, we assessed different preprocedural planning aspects such as patient selection, coronary obstruction risk assessment,
Table 8. Correlates of residual stenosis after ViV TAVI.

\section{Before valve-in-valve}

Stenosis as the baseline mechanism of failure

Preprocedural severe prosthesis-patient mismatch

Stented surgical valve

Small surgical valve (internal diameter $\leq 20 \mathrm{~mm}$ )

During valve-in-valve

Intra-annular transcatheter heart valve

Deep transcatheter heart valve position

Lack of bioprosthetic valve ring fracture

After valve-in-valve

Leaflet thrombosis

Prosthesis-patient mismatch

Structural valve deterioration

and THV selection (Central illustration). Moreover, we analysed relevant procedural features such as prosthesis implantation technique, the role of balloon valve ring fracture, and coronary access.

\section{Conflict of interest statement}

G. Tarantini has received lecture fees from Medtronic, Edwards Lifesciences, Abbott and Boston Scientific. D. Dvir is a consultant 


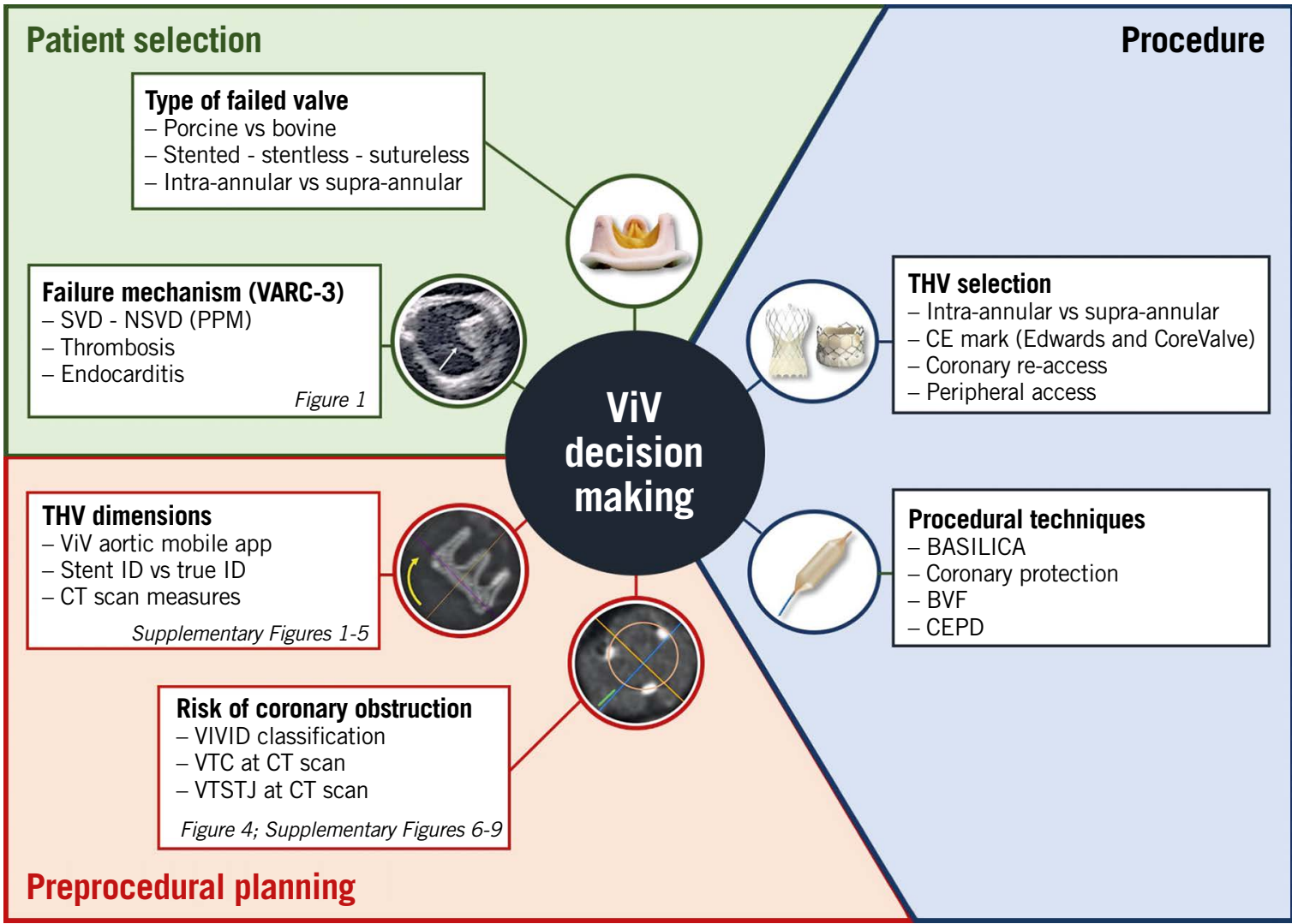

Central illustration. Overview of patient selection, preprocedural evaluation and procedural aspects of valve-in-valve TAVI. BASILICA: bioprosthetic aortic scallop intentional laceration to prevent iatrogenic coronary artery obstruction; BVF: balloon valve fracture; CEPD: cerebral embolic protection device; CT: computed tomography; ID: internal diameter; NSVD: non-structural valve deterioration; SVD: structural valve deterioration; ViV: valve-in-valve; VIVID: Valve-in-Valve International Data; VTC: virtual transcatheter heart valve to coronary distance; VTSTJ: virtual transcatheter heart valve to sinotubular junction distance

to Edwards Lifesciences, Medtronic, Abbott, and PC Cardia. G. Tang is a physician proctor for Medtronic and a consultant for Medtronic, Abbott Structural Heart and W.L. Gore \& Associates.

\section{References}

1. Tarantini G, Nai Fovino L, Gersh BJ. Transcatheter aortic valve implantation in lower-risk patients: what is the perspective? Eur Heart J. 2018;39:658-66.

2. VARC-3 WRITING COMMITTEE, Généreux P, Piazza N, Alu MC, Nazif T, Hahn RT, Pibarot P, Bax JJ, Leipsic JA, Blanke P, Blackstone EH, Finn MT, Kapadia S, Linke A, Majck MJ, Makkar R, Mehran R, Popma JJ, Reardon MJ, Rodés-Cabau J, Van Mieghem NM, Webb JG, Cohen DJ, Leon MB. Valve Academic Research Consortium 3: updated endpoint definitions for aortic valve clinical research. Eur Heart J. 2021;42:1825-57.

3. Bapat VN. Valve-in-Valve app. In: https://www.pcronline.com/PCR-Publications/ PCR-mobile-apps/Valve-in-Valve-Aortic-app. Accessed 1 December 2020.

4. Bapat VN, Attia R, Thomas M. Effect of valve design on the stent internal diameter of a bioprosthetic valve: a concept of true internal diameter and its implications for the valve-in-valve procedure. JACC Cardiovasc Interv. 2014;7:115-27.

5. Dvir D, Leipsic J, Blanke P, Ribeiro HB, Kornowski R, Pichard A, Rodés-Cabau J, Wood DA, Stub D, Ben-Dor I, Maluenda G, Makkar RR, Webb JG. Coronary obstruction in transcatheter aortic valve-in-valve implantation: preprocedural evaluation, device selection, protection, and treatment. Circ Cardiovasc Interv. 2015;8:e02079.

6. Khan JM, Babaliaros BC, Greenbaum AB, Spies C, Daniels D, Depta JP, Oldemeyer B, Whisenant B, McCabe JM, Muhammad KI, George I, Mahoney P, Lanz J, Laham RJ, Shah PB, Chhatriwalla A, Yazdani S, Hanzel G, Pershad A, Leonardi RA, Khalil R, Tang GHL, Herrmann HC, Agarwal S, Fail PS, Zhang M, Pop A, Lisko J, Perdoncin E, Koch RL, Ben-Dor I, Satler LF, Zhang C, Cohen JE,
Lederman RJ, Waksman R, Rogers T. Preventing Coronary Obstruction During Transatheter Aortic Valve Replacement: Results From the Multicenter International BASILICA Registry. JACC Cardiovasc Interv. 2021;14:941-8.

7. Tang GHL, Komatsu I, Tzemach L, Simonato M, Wolak A, Blanke P, Dvir D. Risk of coronary obstruction and the need to perform BASILICA: the VIVID classification. EuroIntervention. 2020;16:e757-9.

8. Simonato M, Webb J, Kornowski R, Vahanian A, Frerker C, Nissen H, Bleiziffer S, Duncan A, Rodés-Cabau J, Attizzani GF, Horlick E, Latib A, Bekeredjian R, Barbanti M, Lefevre T, Cerillo A, Hernández JM, Bruschi G, Spargias K, Iadanza A, Brecker S, Palma JH, Finkelstein A, Abdel-Wahab M, Lemos P, Petronio AS, Champagnac D, Sinning JM, Salizzoni S, Napodano M, Fiorina C, Marzocchi A, Leon M, Dvir D. Transcatheter Replacement of Failed Bioprosthetic Valves: Large Multicenter Assessment of the Effect of Implantation Depth on Hemodynamics After Aortic Valve-in-Valve. Circ Cardiovasc Interv. 2016;9:e003651.

9. Azadani AN, Reardon M, Simonato M, Aldea G, Nickenig G, Kornowski R, Dvir D Effect of transcatheter aortic valve size and position on valve-in-valve hemodynamics: An in vitro study. $J$ Thorac Cardiovasc Surg. 2017;153:1303-15.

10. Simonato M, Webb J, Bleiziffer S, Abdel-Wahab M, Wood D, Seiffert M, Schäfer U, Wöhrle J, Jochheim D, Woitek F, Latib A, Barbanti M, Spargias K, Kodali S, Jones T, Tchetche D, Coutinho R, Napodano M, Garcia S, Veulemans V, Siqueira D, Windecker S, Cerillo A, Kempfert J, Agrifoglio M, Bonaros N, Schoels W, Baumbach H, Schofer J, Gaia DF, Dvir D. Current Generation Balloon-Expandable Transcatheter Valve Positioning Strategies During Aortic Valve-in-Valve Procedures and Clinical Outcomes. JACC Cardiovasc Interv. 2019;12:1606-17.

11. Allen KB, Chhatriwalla AK, Cohen DJ, Saxon JT, Aggarwal S, Hart A, Baron S, Davis JR, Pak AF, Dvir D, Borkon AM. Bioprosthetic Valve Fracture to Facilitate Transcatheter Valve-in-Valve Implantation. Ann Thorac Surg. 2017;104:1501-8.

12. Chhatriwalla AK, Sorajja P. Expanding Indications for Bioprosthetic Valve Fracture and Bioprosthetic Valve Remodeling. Circ Cardiovasc Interv. 2018;11:e07017. 
13. Ziccardi MR, Groves EM. Bioprosthetic Valve Fracture for Valve-in-Valve Transcatheter Aortic Valve Replacement: Rationale, Patient Selection, Technique, and Outcomes. Interv Cardiol Clin. 2019;8:373-82.

14. Eitan A, Brinkmann C, Haselbach T, Witt J, Schofer J. Does valve in valve TAVR carry a higher risk for thromboembolic events compared to native valve TAVR? Catheter Cardiovasc Interv. 2020;95:1017-21.

15. Tarantini G, Fabris T, Nai Fovino L. TAVR-in-TAVR and coronary access: importance of preprocedural planning. EuroIntervention. 2020;16:e129-32.

16. Nai Fovino L, Scotti A, Massussi M, Cardaioli F, Rodinò G, Matsuda Y, Pavei A, Masiero G, Napodano M, Fraccaro C, Fabris T, Tarantini G. Coronary Angiography After Transcatheter Aortic Valve Replacement (TAVR) to Evaluate the Risk of Coronary Access Impairment After TAVR-in-TAVR. J Am Heart Assoc. 2020;9: e016446.

17. Tarantini G, Nai Fovino L. Coronary Access and TAVR-in-TAVR: Don't Put Off Until Tomorrow What You Can Do Today. JACC Cardiovasc Interv. 2020;13: 2539-41.

18. Tang GHL, Zaid S, Gupta E, Ahmad H, Khan A, Kovacic JC, Lansman SL, Dangas GD, Sharma SK, Kini A. Feasibility of Repeat TAVR After SAPIEN 3 TAVR: A Novel Classification Scheme and Pilot Angiographic Study. JACC Cardiovasc Interv. 2019;12:1290-2.

19. Tarantini G, Nai Fovino L, Le Prince P, Darremont O, Urena M, Bartorelli AL, Vincent F, Hovorka T, Alcalá Navarro Y, Dumonteil N, Ohlmann P, Wendler O. Coronary Access and Percutaneous Coronary Intervention Up to 3 Years After Transcatheter Aortic Valve Implantation With a Balloon-Expandable Valve. Circ Cardiovasc Interv. 2020;13:e008972.

20. Tarantini G, Fabris T, Cardaioli F, Nai Fovino L. Coronary Access After Transcatheter Aortic Valve Replacement in Patients With Bicuspid Aortic Valve: Lights and Shades. JACC Cardiovasc Interv. 2019;12:1190-1.

21. Nai Fovino L, Scotti A, Massussi M, Fabris T, Cardaioli F, Rodinò G, Matsuda Y, Frigo F, Fraccaro C, Tarantini G. Incidence and feasibility of coronary access after transcatheter aortic valve replacement. Catheter Cardiovasc Interv. 2020;96:E535-41. 22. Tang GHL, Zaid S, Fuchs A, Yamabe T, Yazdchi F, Gupta E, Ahmad H, Kofoed KF, Goldberg JB, Undemir C, Kaple RK, Shah PB, Kaneko T, Lansman SL, Khera S, Kovacic JC, Dangas GD, Lerakis S, Sharma SK, Kini A, Adams DH, Khalique OK, Hahn RT, Søndergaard L, George I, Kodali SK, De Backer O, Leon MB, Bapat VN. Alignment of Transcatheter Aortic-Valve Neo-Commissures (ALIGN TAVR): Impact on Final Valve Orientation and Coronary Artery Overlap. JACC Cardiovasc Interv. 2020;13:1030-42.

23. Tuzcu EM, Kapadia SR, Vemulapalli S, Carroll JD, Holmes DR Jr, Mack MJ, Thourani VH, Grover FL, Brennan JM, Suri RM, Dai D, Svensson LG. Transcatheter Aortic Valve Replacement of Failed Surgically Implanted Bioprostheses: The STS/ ACC Registry. J Am Coll Cardiol. 2018;72:370-82.

24. Duncan A, Moat N, Simonato M, de Weger A, Kempfert J, Eggebrecht H, Walton A, Hellig F, Kornowski R, Spargias K, Mendiz O, Makkar R, Guerrero M, Rihal C, George I, Don C, Iadanza A, Bapat V, Welsh R, Wijeysundera HC, Wood D, Sathananthan J, Danenberg H, Maisano F, Garcia S, Gafoor S, Nombela-Franco L, Cobiella J, Dvir D. Outcomes Following Transcatheter Aortic Valve Replacement for Degenerative Stentless Versus Stented Bioprostheses. JACC Cardiovasc Interv. 2019; 12:1256-63.

25. Dvir D, Webb JG, Bleiziffer S, Pasic M, Waksman R, Kodali S, Barbanti M, Latib A, Schaefer U, Rodés-Cabau J, Treede H, Piazza N, Hildick-Smith D, Himbert D, Walther T, Hengstenberg C, Nissen H, Bekeredjian R, Presbitero P, Ferrari E, Segev A, de Weger A, Windecker S, Moat NE, Napodano M, Wilbring M, Cerillo AG, Brecker S, Tchetche D, Lefèvre T, De Marco F, Fiorina C, Petronio AS, Teles RC, Testa L, Laborde JC, Leon MB, Kornowski R; Valve-in-Valve International Data Registry Investigators. Transcatheter aortic valve implantation in failed bioprosthetic surgical valves. JAMA. 2014;312:162-70.

26. Webb JG, Murdoch DJ, Alu MC, Cheung A, Crowley A, Dvir D, Herrmann HC, Kodali SK, Leipsic J, Miller DC, Pibarot P, Suri RM, Wood D, Leon MB, Mack MJ. 3-Year Outcomes After Valve-in-Valve Transcatheter Aortic Valve Replacement for Degenerated Bioprostheses: The PARTNER 2 Registry. J Am Coll Cardiol. 2019;73: 2647-55.

27. Yao RJ, Simonato M, Dvir D. Optimising the Haemodynamics of Aortic Valve-invalve Procedures. Interv Cardiol. 2017;12:40-3.
28. Bleiziffer S, Simonato M, Webb JG, Rodés-Cabau J, Pibarot P, Kornowski R, Windecker S, Erlebach M, Duncan A, Seiffert M, Unbehaun A, Frerker C, Conzelmann L, Wijeysundera H, Kim WK, Montorfano M, Latib A, Tchetche D, Allali A, Abdel-Wahab M, Orvin K, Stortecky S, Nissen H, Holzamer A, Urena M, Testa L, Agrifoglio M, Whisenant B, Sathananthan J, Napodano M, Landi A, Fiorina C, Zittermann A, Veulemans V, Sinning JM, Saia F, Brecker S, Presbitero P, De Backer O, Søndergaard L, Bruschi G, Franco LN, Petronio AS, Barbanti M, Cerillo A, Spargias K, Schofer J, Cohen M, Muñoz-Garcia A, Finkelstein A, Adam M, Serra V, Teles RC, Champagnac D, Iadanza A, Chodor P, Eggebrecht H, Welsh R, Caixeta A, Salizzoni S, Dager A, Auffret V, Cheema A, Ubben T, Ancona M, Rudolph T, Gummert J, Tseng E, Noble S, Bunc M, Roberts D, Kass M, Gupta A, Leon MB, Dvir D. Long-term outcomes after transcatheter aortic valve implantation in failed bioprosthetic valves. Eur Heart J. 2020;41:2731-42.

\section{Supplementary data}

Supplementary Figure 1. Images of commonly used surgical aortic valves (SAVs) and respective depictions under fluoroscopy.

Supplementary Figure 2. Images of commonly used sutureless SAVs and respective depictions under fluoroscopy.

Supplementary Figure 3. Images of commonly used stentless SAVs and aortic root replacement prostheses.

Supplementary Figure 4. Sample workflow of the valve-in-valve app, available for free download on both Apple and Android platforms.

Supplementary Figure 5. Step-by-step approach to measure internal diameters of bioprosthetic SAVs by computed tomography.

Supplementary Figure 6. VIVID classification.

Supplementary Figure 7. Step-by-step approach to estimate the risk of coronary obstruction after valve-in-valve procedure by computed tomography assessment of virtual transcatheter heart valve (THV) to coronary distance (VTC), virtual THV to sinotubular junction (STJ) distance (VTSTJ), and coronary artery height.

Supplementary Figure 8. Degeneration of a stented bioprosthetic aortic valve treated with valve-in-valve implantation of a SAPIEN 3 transcatheter heart valve (THV).

Supplementary Figure 9. Case examples of valve-in-valve procedure with different techniques of coronary protection in diverse aortic root anatomies and SAV types.

Supplementary Figure 10. Case examples of valve-in-valve procedure in complex scenarios.

Supplementary Table 1. Summary of main anatomical characteristics and measures to evaluate in preprocedural CT scan.

Supplementary Table 2. Stented surgical aortic valves that can undergo balloon valve fracture (BVF), cannot undergo BVF but can undergo balloon valve remodelling (BVR), and cannot undergo $\mathrm{BVF}$ or BVR.

The supplementary data are published online at:

https://eurointervention.pcronline.com/

doi/10.4244/EIJ-D-21-00157 
A

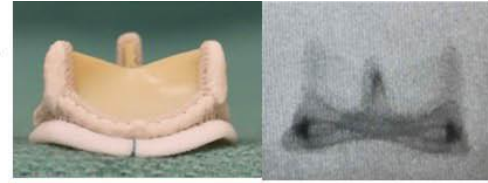

B

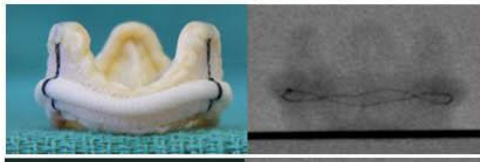

C

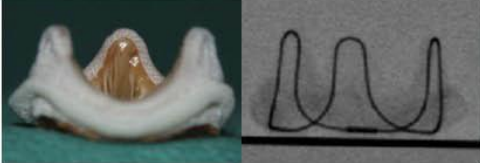

D

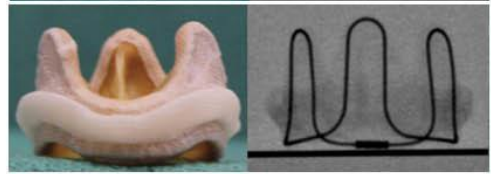

E

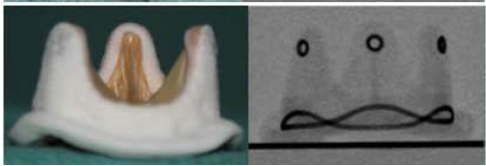

$\mathbf{F}$

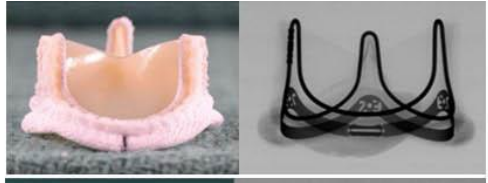

G

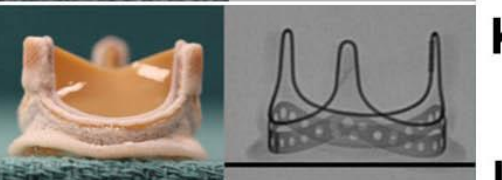

H

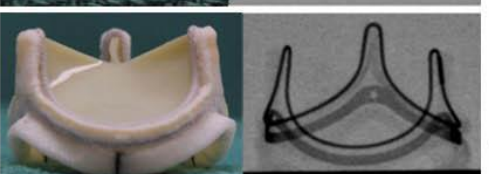

I

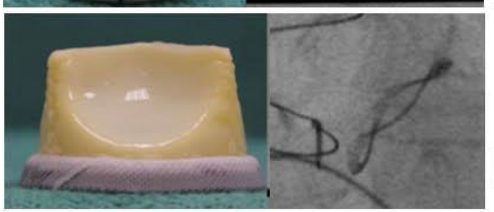

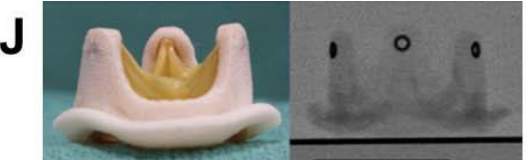

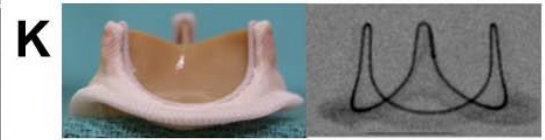

$\mathbf{L}$

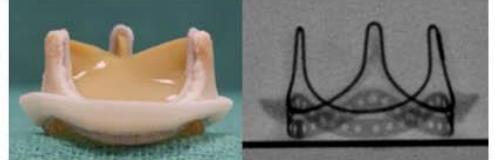

M

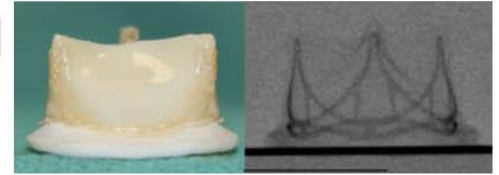

$\mathbf{N}$

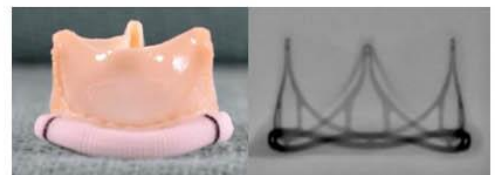

Supplementary Figure 1. Images of commonly used surgical aortic valves (SAV) and respective depictions under fluoroscopy.

Stented SAV:

A) Avalus ${ }^{\mathrm{TM}}$ (Medtronic, Minneapolis, MN, USA).

B) Biocor ${ }^{\circledR} /$ Epic $^{\text {TM }}$ (Abbott, Minneapolis, MN, USA).

C) CE SAV (Edwards Lifesciences, Irvine, CA, USA).

D) CE Standard 2625 (Edwards Lifesciences).

E) Hancock ${ }^{\circledR}$ II (Medtronic).

F) INSPIRIS (Edwards Lifesciences).

G) Magna 3000 (Edwards Lifesciences).

H) Magna Ease 3300 (Edwards Lifesciences).

I) Mitroflow (LivaNova, London, UK).

J) Mosaic (Medtronic).

K) PERIMOUNT 2700 (Edwards Lifesciences).

L) PERIMOUNT 2800 (Edwards Lifesciences).

M) $\operatorname{Trifecta}^{\mathrm{TM}}$ (Abbott).

N) Trifecta ${ }^{\mathrm{TM}}$ GT (Abbott). 


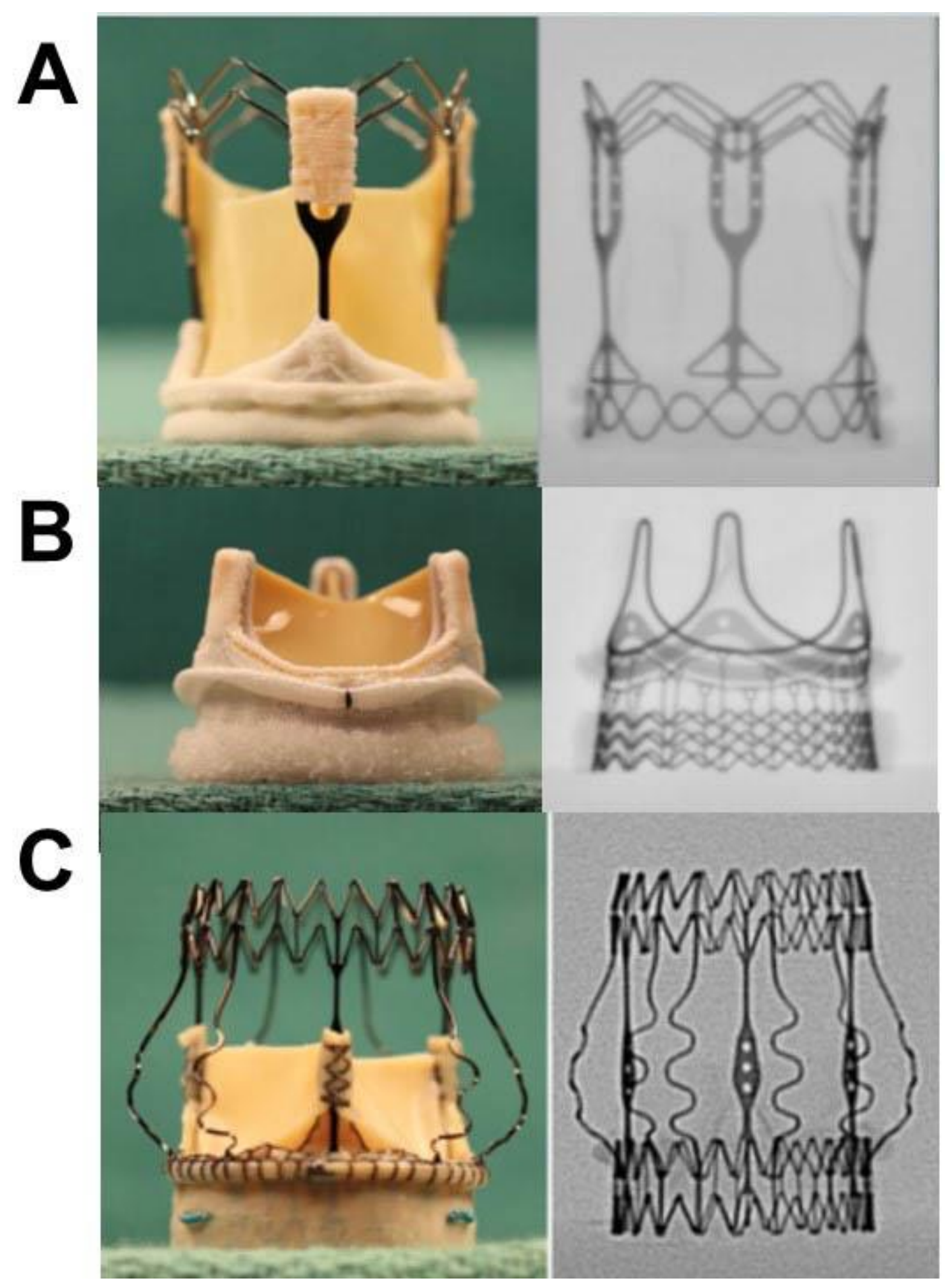

Supplementary Figure 2. Images of commonly used sutureless surgical aortic valves (SAV) and respective depictions under fluoroscopy.
A) $3 \mathrm{f} \mathrm{Enable}^{\mathrm{TM}}$ (ATS, Minneapolis, MN, USA).
B) INTUITY (Edwards Lifesciences).
C) Perceval (Sorin). 

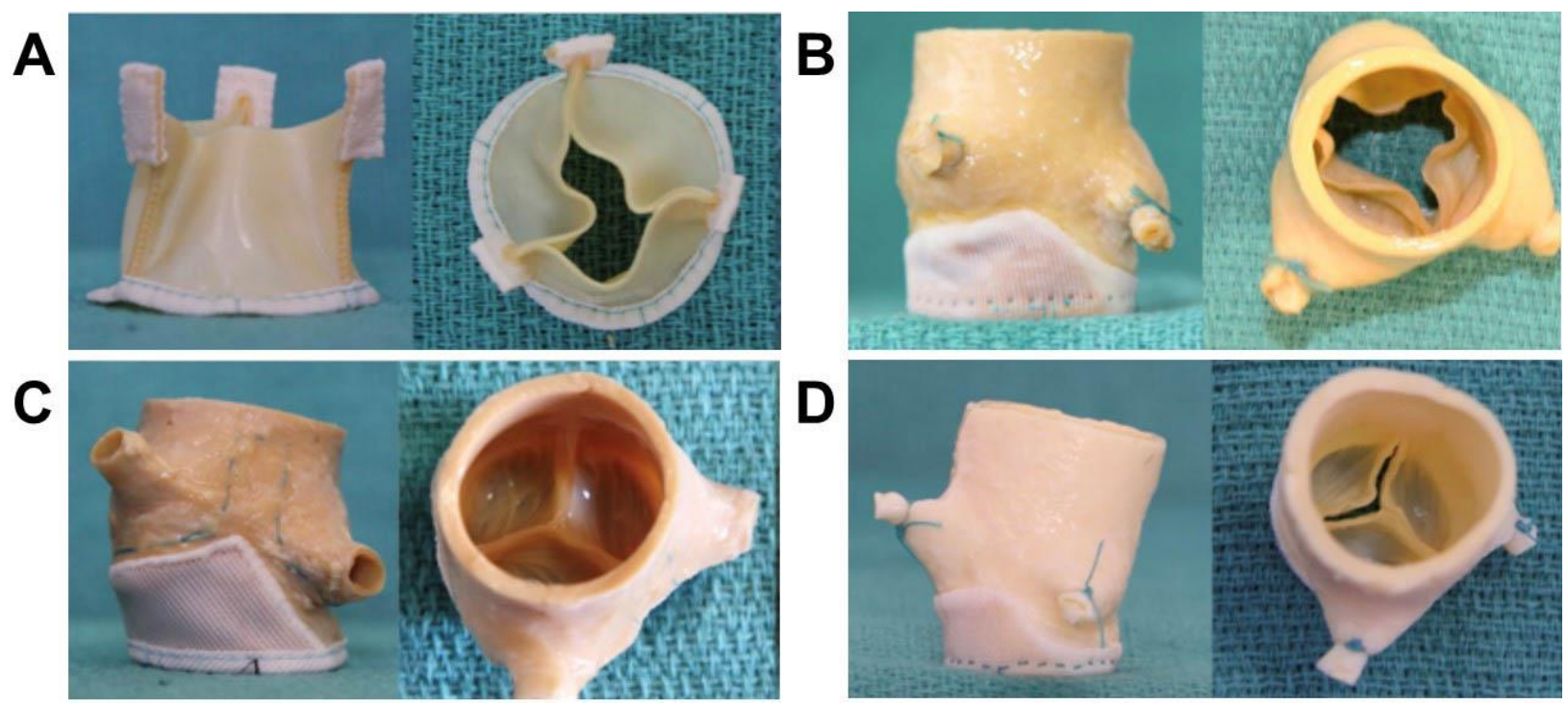

Supplementary Figure 3. Images of commonly used stentless surgical aortic valves (SAV) and aortic root replacement prostheses.
A) 3f Enable (ATS).
B) Freestyle (Medtronic).
C) Prima (Edwards Lifesciences).
D) Toronto SPV (Medtronic). 


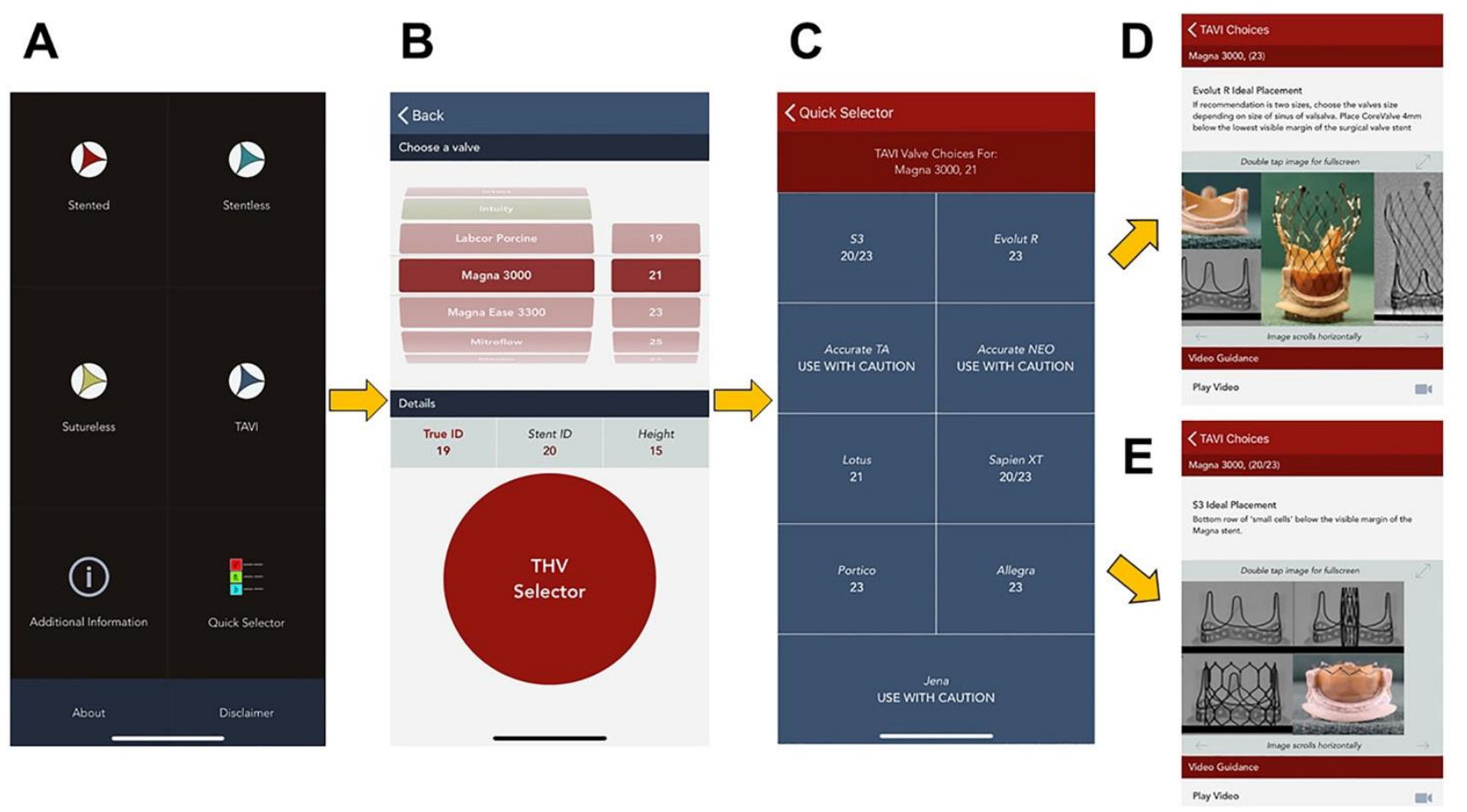

Supplementary Figure 4. Sample workflow of the valve-in-valve app, available for free download on both Apple and Android platforms.
A) Main screen.
B) Quick Selector interface, where one can scroll across the different surgical aortic valves and sizes to reveal the frame internal diameter and height.
C) Clicking the transcatheter heart valve (THV) selector reveals the appropriate TAVI valve choices and sizes for a particular SAV model and size, in this case a $21 \mathrm{~mm}$ Magna 3000 SAV.
D) Image of an Evolut R THV optimally placed inside the Magna $3000 \mathrm{SAV}$.
E) Image of a SAPIEN 3 THV optimally placed inside the Magna 3000 SAV. 


\section{Step 1}

Start out with multi-planar images in default axial, sagittal and

coronal orientation; center cross-

hairs onto the prosthetic valve;

align the cross-hairs in the

sagittal and coronal views with

the long axis of the aortic root; the

resulting double oblique

transverse view will depict the

prosthetic valve en face.

\section{Step 2}

Increase the slide tickness to obtain a volume rendering visualization of the prosthetic valve stent strut.

\section{Step 3}

Rotate the cross-hairs in the double-oblique transverse view and center the cross-hairs in th sagittal and coronal views to transect excatly the mid-portion ring of the prosthetic valve.

\section{Step 4}

Repeat the Step 3 until a $360^{\circ}$ rotation; once this is achieved, the transverse double-oblique axis will be exactly aligned with the basal ring of the prosthetic valve.
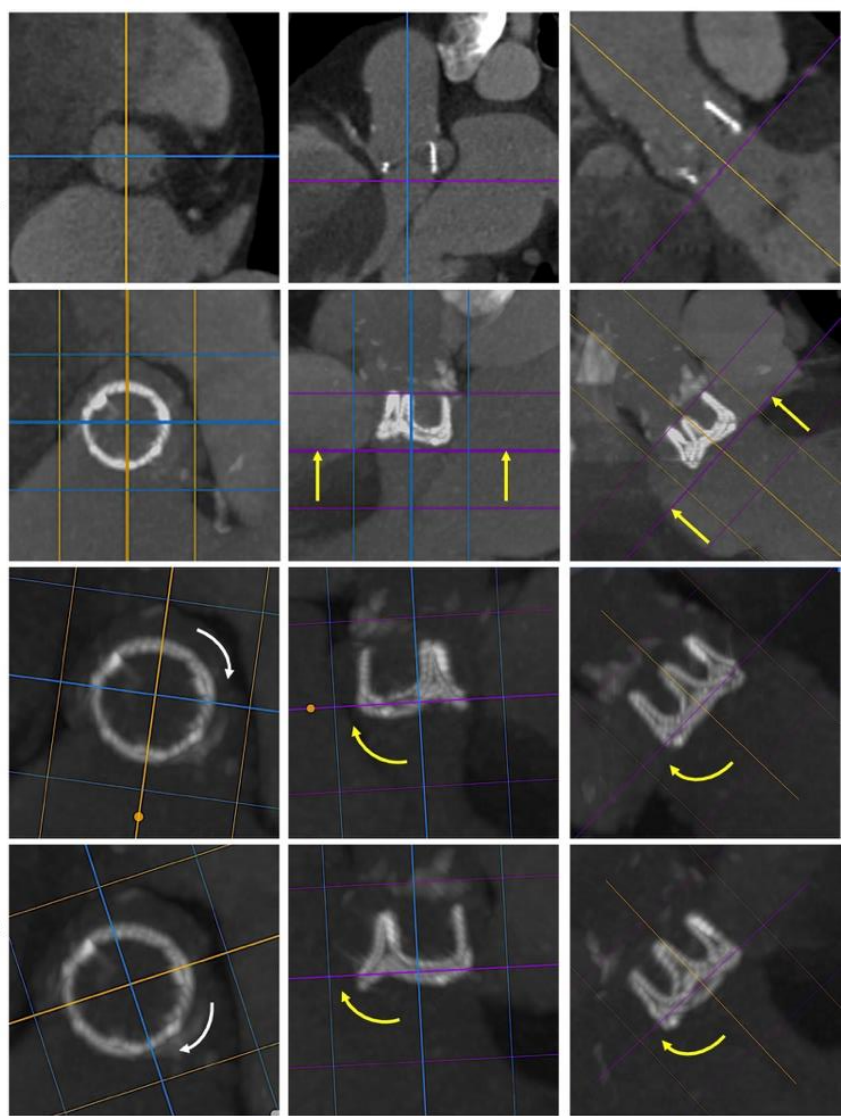

\section{Step 5}

Reduce the slide tickness to obtain a 2-Dimensional

visualization of the prosthetic valve.
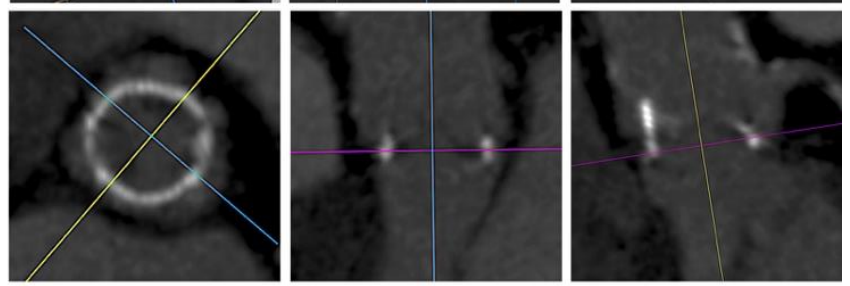

\section{Step 6}

Measure the internal diameters of the valve ring.
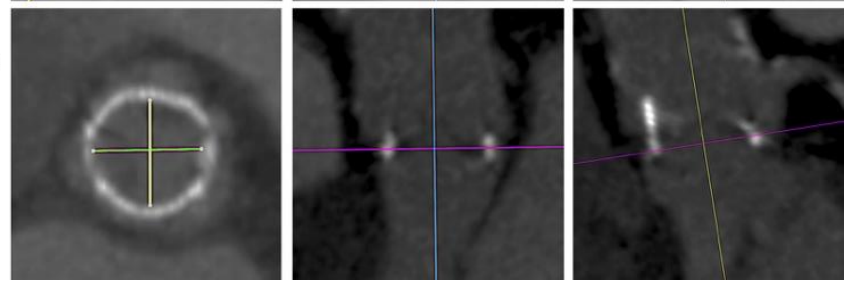

Supplementary Figure 5. Step-by-step approach to measure internal diameters of bioprosthetic surgical aortic valves by computed tomography. 

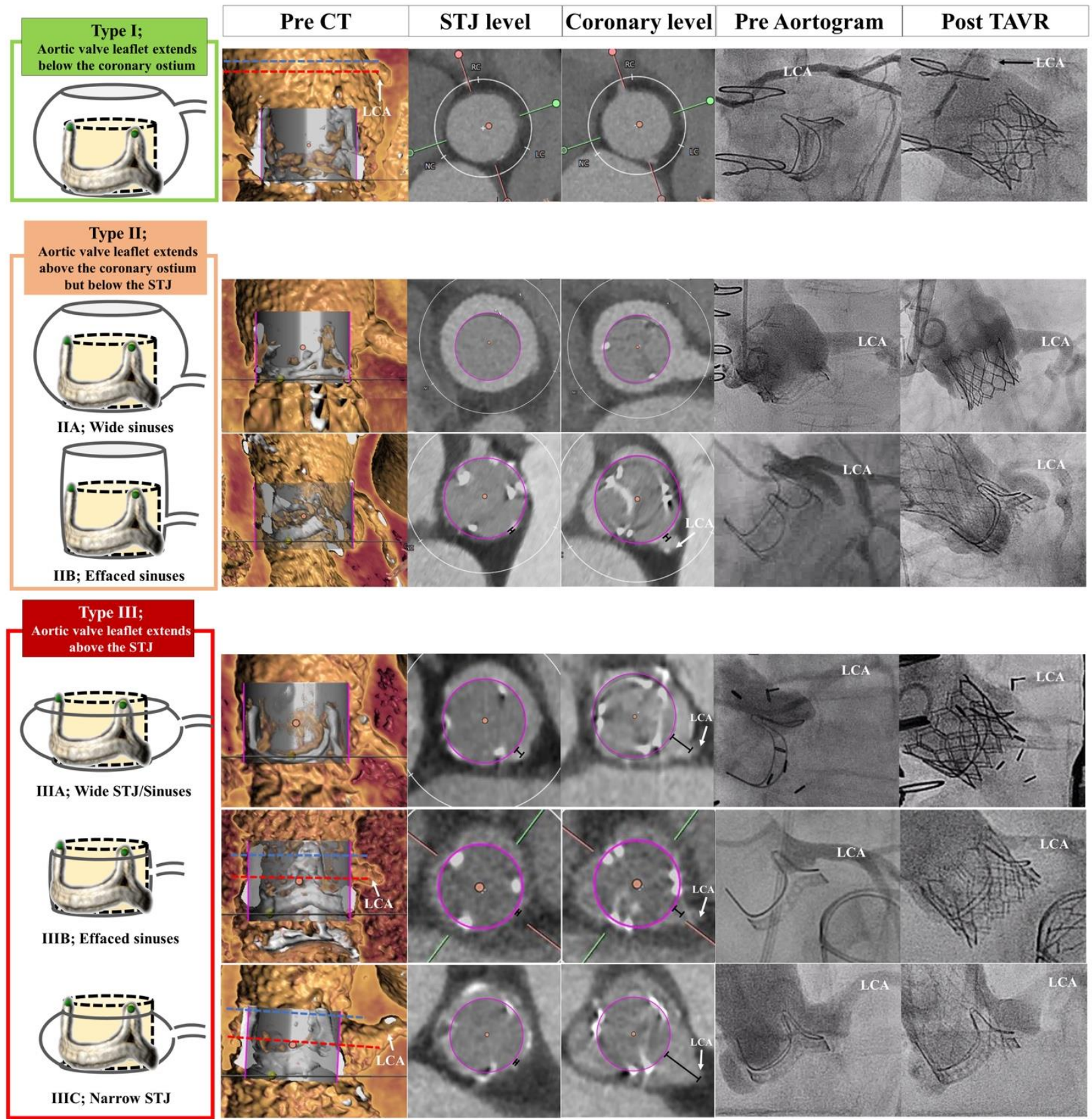

Supplementary Figure 6. VIVID classification.

Anatomic classification of the aortic root and valve leaflet position to determine the possible need for BASILICA during transcatheter aortic valve implantation (TAVI). Each coronary artery ostium would need to be classified separately [7]. 


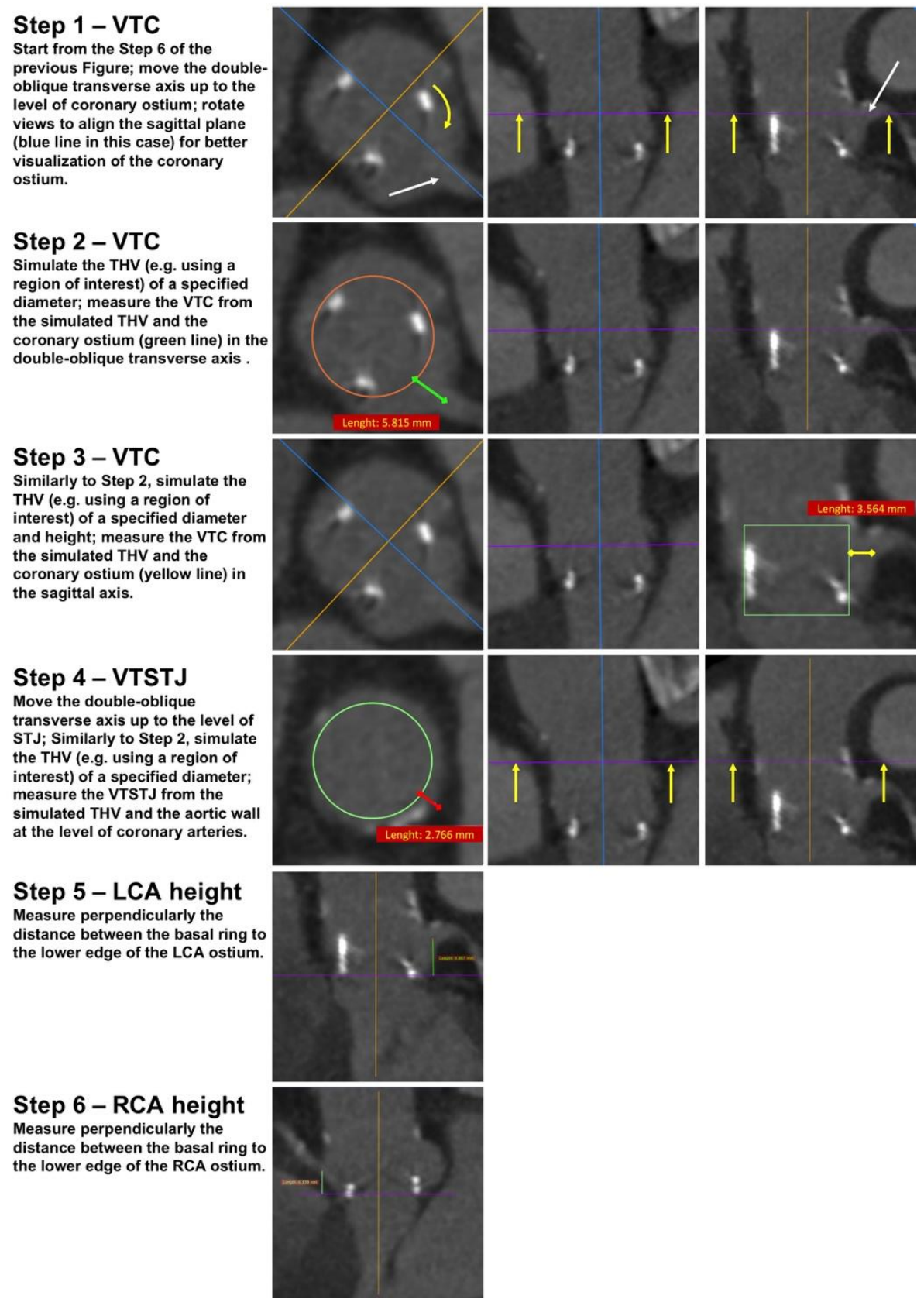

Supplementary Figure 7. Step-by-step approach to estimate the risk of coronary obstruction after valve-in-valve procedure by computed tomography assessment of virtual transcatheter heart valve (THV) to coronary distance (VTC), virtual THV to sinotubular junction (STJ) distance (VTSTJ), and coronary artery height.

For stented surgical aortic valves (SAVs), VTC assessment is only required if the coronary artery orifices are located at or below the tip of the stent posts. For sutureless SAVs a traditional coronary height/SoV-width assessment is performed. 

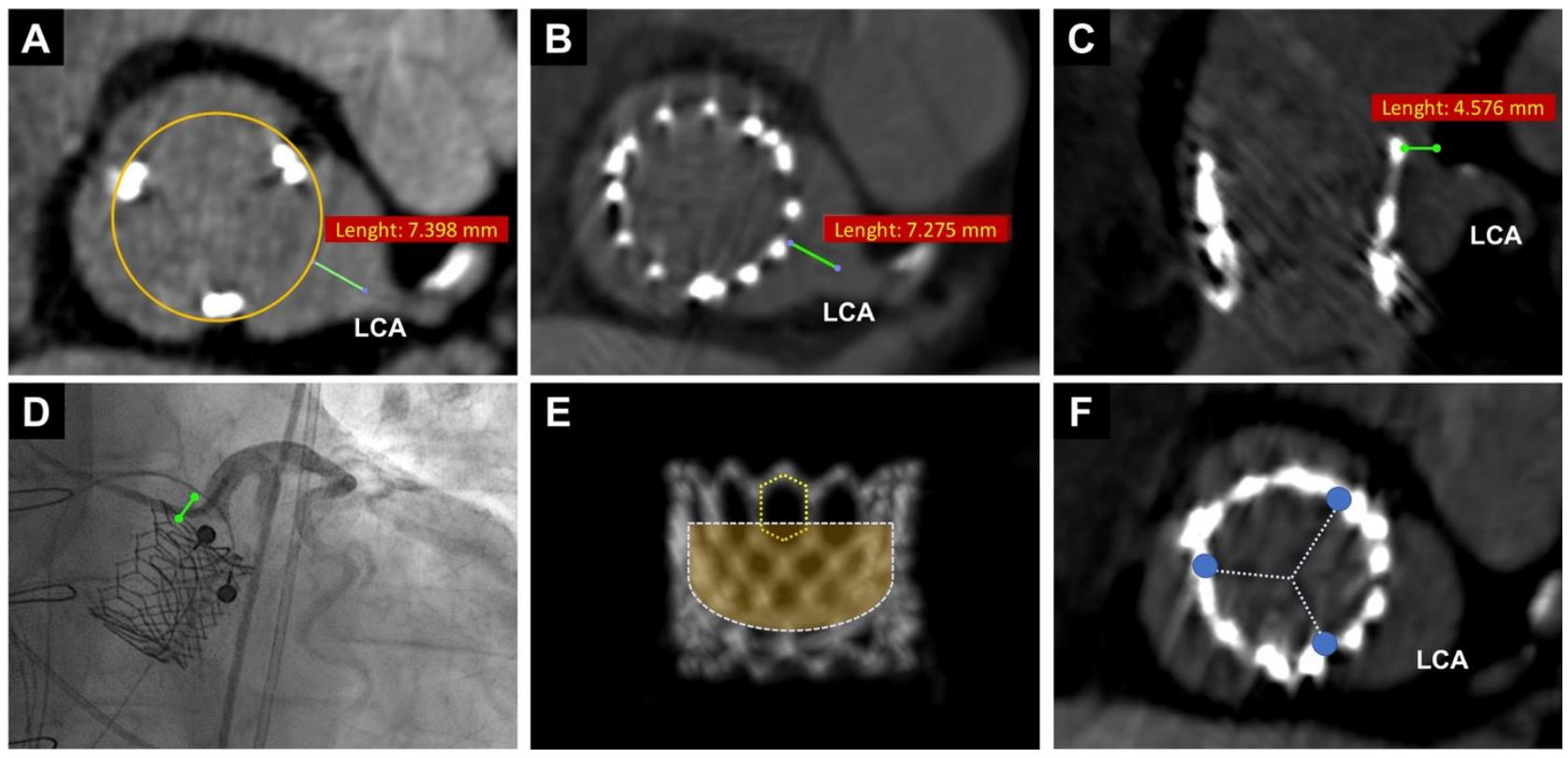

Supplementary Figure 8. Degeneration of a stented bioprosthetic aortic valve treated with valvein-valve implantation of a SAPIEN 3 transcatheter heart valve (THV).

Left coronary artery (LCA) below the risk plane, but with a low risk of coronary obstruction as predicted by the virtual THV to coronary distance (VTC) $>4 \mathrm{~mm}$ (A). Good predictive value and reproducibility of the VTC as confirmed by post-procedural computed tomography (CT) scan (B). Important to have an adequate distance between the THV and the aortic wall at the level of the sinotubular junction to guarantee both coronary perfusion and easier coronary access after valve-invalve implantation (C \& D). CT depiction of further factors potentially impacting on the coronary access after valve-in-valve procedure: open-cell design of upper stent frame of SAPIEN 3 THV (E) and optimal (random) commissural alignment with respect to the LCA ostium (F). 
A

- Stented SAV

- Coronary take off above the risk plane

- No coronary protection need

\section{B}

- Stented SAV

- Coronary take off below the risk plane

- VTC $>4 \mathrm{~mm}$ and $<6 \mathrm{~mm}$

- Coronary protection with guidewire only

\section{C}

D

- Stentless SAV

- Coronary take off below the risk plane

- VTC<4 mm

- Coronary protection with both guidewire and stent in place for bailout Chimney stenting

- Stentless SAV

- Coronary take off below the risk plane

- VTC<4 mm

- Coronary protection with both guidewire and stent in place for bailout Chimney stenting
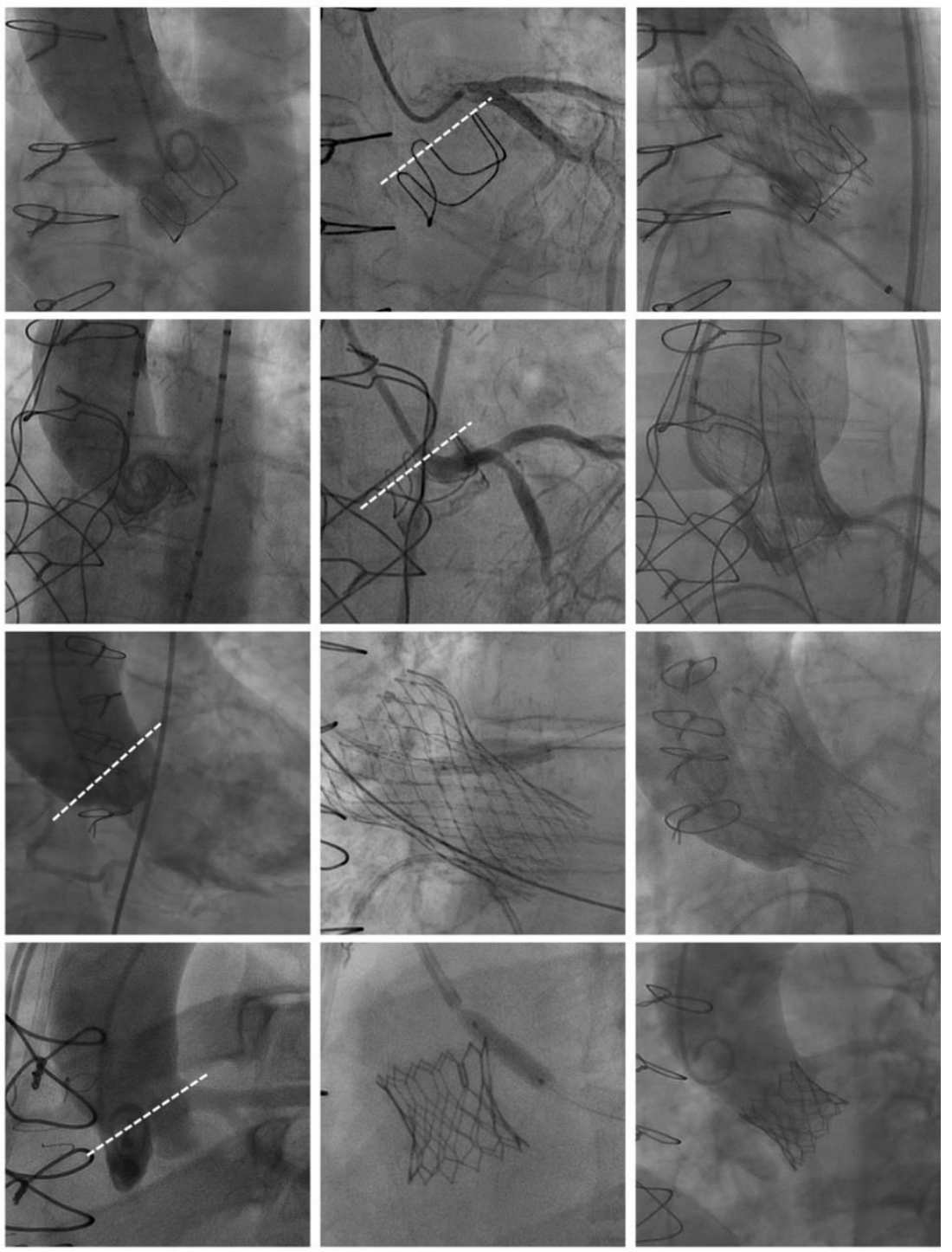

Supplementary Figure 9. Case examples of valve-in-valve procedure with different techniques of coronary protection in diverse aortic root anatomies and surgical aortic valve (SAV) types.

Case A. Degenerated stented SAV and LCA ostium above the risk plane (dotted line). Coronary protection during valve-in-valve procedure was not needed. No coronary obstruction after implantation of a CoreValve transcatheter heart valve (THV).

Case B. Degenerated stented SAV and LCA ostium below the risk plane (dotted line). Intermediate risk of coronary obstruction as anticipated by a virtual THV to coronary distance (VTC) between 4 and $6 \mathrm{~mm}$. Coronary protection with guidewire only during valve-in-valve procedure. No coronary obstruction after implantation of a CoreValve THV.

Case C. Degenerated stentless SAV and LCA ostium below the risk plane (dotted line). High risk of coronary obstruction as anticipated by a VTC below $4 \mathrm{~mm}$. Coronary protection with both guidewire and stent in place before valve-in-valve procedure. Bail-out stenting of LCA by chimney technique due to coronary flow impairment after deployment of a high stent-frame self-expanding CoreValve THV. 
Case D. Degenerated stentless SAV and LCA ostium below the risk plane (dotted line). High risk of coronary obstruction as anticipated by a VTC below $4 \mathrm{~mm}$. Coronary protection with both guidewire and stent in place before valve-in-valve procedure. Bail-out stenting of LCA by chimney technique due to coronary flow impairment after deployment of a low stent-frame balloonexpandable SAPIEN 3 THV. Note the theoretically easier (than taller frame devices) coronary cannulation with the use of low stent-frame THVs in high-risk anatomies for coronary flow and access impairment after valve-in-valve procedure. 

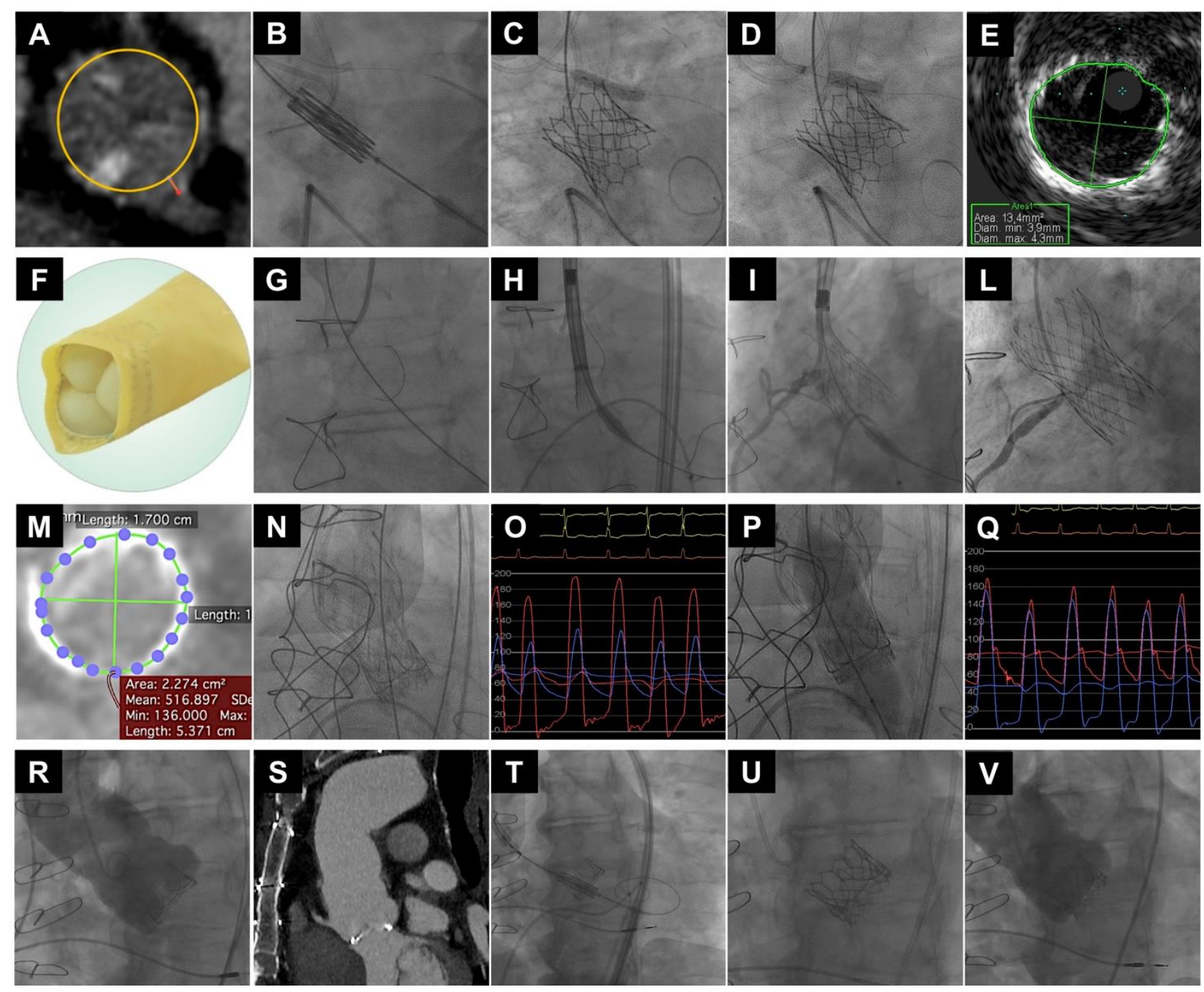

Supplementary Figure 10. Case examples of valve-in-valve procedure in complex scenarios.

Panels A-E.

A) Degenerated stenotic stentless SAV (Freedom SOLO $21 \mathrm{~mm}$ [Sorin]) with high risk of coronary obstruction (VTC $<3 \mathrm{~mm}$ for both LCA and RCA).

B) SAPIEN 3 THV $23 \mathrm{~mm}$ ( $2 \mathrm{cc}$ less) deployment with coronary protection of both coronaries by positioning of guidewire and stent.

C) Bail-out LCA stenting (chimney technique) with optimisation by stent post-dilation (D).

E) Optimal final result as confirmed by post-procedural IVUS.

Panels F-L.

F) Degenerated regurgitant stentless SAV (Shelhigh BioConduit ${ }^{\mathrm{TM}} 29 \mathrm{~mm}$ [Shelhigh Inc., Union, $\mathrm{NJ}, \mathrm{USA}]$ ) due to non-coronary cusp prolapse and with intermediate risk of RCA obstruction (VTC between 4 and $6 \mathrm{~mm}$ ).

G) RCA protection with guidewire only and positioning of a second guidewire into the right sinus to mark the nadir of the cusp, because of the absence of a radiopaque bioprosthetic ring.

H) \& I) Slow deployment of the selected CoreValve Evolut R $34 \mathrm{~mm}$ THV.

L) Optimal final result with RCA patency and successful selective cannulation. 


\section{Panels M-Q.}

M) Degenerated stenotic stented SAV of small size (Magna $19 \mathrm{~mm}$ ) with intermediate risk of LCA obstruction (VTC between 4 and $6 \mathrm{~mm}$ ) and anticipated risk of high residual gradients.

N) Correct implantation of the selected CoreValve Evolut R $23 \mathrm{~mm}$ THV.

O) High residual transprosthetic gradients.

P) Balloon valve ring fracture attempt by inflation at high pressure of a non-compliant True Dilatation balloon, $21 \mathrm{~mm}$ (Becton Dickinson).

Q) Optimal final result with acceptable residual transprosthetic gradients.

Panels R-V.

R) \& S) Degenerated stenotic stented SAV (Magna $25 \mathrm{~mm}$ ) in the presence of a significant kinking of the ascending aorta prosthesis.

T) Easy implantation of a SAPIEN 3 THV $(26 \mathrm{~mm})$ due to its favourable steering flex delivery catheter.

U) \& V) Optimal final THV positioning.

IVUS: intravascular ultrasound; LCA: left coronary artery; RCA: right coronary artery; SAV: surgical aortic valve; THV: transcatheter heart valve; VTC: virtual transcatheter heart valve to coronary distance 
Supplementary Table 1. Summary of main anatomical characteristics and measures to evaluate in preprocedural CT scan.

\begin{tabular}{|c|c|}
\hline Item & Required information \\
\hline Surgical aortic valve & $\begin{array}{ll}\text { - } & \text { Type (stented vs stentless vs sutureless) } \\
\text { - } & \text { Mechanism of SVD (extent and degree of } \\
\text { calcification; leaflet flail; pannus vs } \\
\text { thrombosis) } \\
\text { - } & \text { Stent ID } \\
\text { - } & \text { True ID } \\
- & \text { Leaflet length and thickness }\end{array}$ \\
\hline Coronary arteries & $\begin{array}{l}\text { - Shortest distance from valve ring to ostia } \\
\text { of LCA and RCA } \\
\text { - } \\
\text { Presence and course of anomalous } \\
\text { coronary arteries } \\
\text { - VTC (needed when coronary arteries lie } \\
\text { below the surgical valve posts or in any } \\
\text { case of sutureless valves) }\end{array}$ \\
\hline Aortic root & $\begin{array}{l}\text { SOV height } \\
\text { - } \quad \text { SOV width } \\
\text { VTSTJ (needed when the surgical valve } \\
\text { posts extend above the STJ) }\end{array}$ \\
\hline Ascending aorta & $\begin{array}{l}\text { - Dimensions } \\
\text { - Angulation between ascending aorta and } \\
\text { LVOT } \\
\text { - Presence of vascular prosthesis (and } \\
\text { possible kinking or angulation) }\end{array}$ \\
\hline Iliofemoral access route & $\begin{array}{ll}\text { - } & \text { Minimal diameters } \\
\text { - } & \text { Calcifications } \\
\text { - } & \text { Tortuosity }\end{array}$ \\
\hline
\end{tabular}

CT: computed tomography; ID: internal diameter; LCA: left coronary artery; LVOT: left ventricle outflow tract; RCA: right coronary artery; SOV: sinus of Valsalva; STJ: sinotubular junction; SVD: surgical valve dysfunction; VTC: virtual transcatheter heart valve to coronary distance; VTSTJ: virtual transcatheter heart valve to sinotubular junction distance 
Supplementary Table 2. Stented surgical aortic valves that can undergo balloon valve fracture (BVF), cannot undergo BVF but can undergo balloon valve remodelling (BVR), and cannot undergo BVF or BVR.

\begin{tabular}{|l|l|l|}
\hline \multicolumn{1}{|c|}{ Yes BVF } & \multicolumn{1}{|c|}{ No BVF but Yes BVR } & \multicolumn{1}{|c|}{ No BVR or BVR } \\
\hline Porcine & Porcine & Porcine \\
Biocor & CE SAV & Hancock II \\
Epic & CE standard 2625 & Bovine pericardial, internally \\
Mosaic & Bovine pericardial, internally & mounted \\
Lvalus \\
Labcor TLPB & mounted & \\
Bovine pericardial, internally & PERIMOUNT 2700 & \\
mounted & INSPIRIS* & \\
PERIMOUNT 2800 & Bovine pericardial, externally & \\
Magna 3000 & mounted & \\
Magna Ease 3300 & Trifecta & \\
Bovine pericardial, externally & Trifecta GT & \\
mounted & & \\
Dokimos (Labcor, Belo & & \\
Horizonte, Brazil) & & \\
Mitroflow & & \\
\hline
\end{tabular}

*INSPIRIS has an expandable hinge that can expand with balloon dilatation. No clinical experience has been reported.

CE: Carpentier-Edwards 